\title{
Genome-wide identification of microRNA and siRNA responsive to endophytic beneficial diazotrophic bacteria in maize
}

Flávia Thiebaut ${ }^{1 \dagger}$, Cristian A Rojas $^{2 \dagger}$, Clícia Grativol ${ }^{1}$, Mariana Romeiro Motta ${ }^{1}$, Tauan Vieira ${ }^{1}$, Michael Regulski ${ }^{3}$, Robert A Martienssen ${ }^{3}$, Laurent Farinelli ${ }^{4}$, Adriana S Hemerly ${ }^{1}$ and Paulo CG Ferreira ${ }^{\text {** }}$

\begin{abstract}
Background: Small RNA (sRNA) has been described as a regulator of gene expression. In order to understand the role of maize sRNA (Zea mays - hybrid UENF 506-8) during association with endophytic nitrogen-fixing bacteria, we analyzed the sRNA regulated by its association with two diazotrophic bacteria, Herbaspirillum seropedicae and Azospirillum brasilense.

Results: Deep sequencing analysis was done with RNA extracted from plants inoculated with $H$. seropedicae, allowing the identification of miRNA and siRNA. A total of 25 conserved miRNA families and 15 novel miRNAs were identified. A dynamic regulation in response to inoculation was also observed. A hypothetical model involving copper-miRNA is proposed, emphasizing the fact that the up-regulation of miR397, miR398, miR408 and miR528, which is followed by inhibition of their targets, can facilitate association with diazotrophic bacteria. Similar expression patterns were observed in samples inoculated with A. brasilense. Moreover, novel miRNA and siRNA were classified in the Transposable Elements (TE) database, and an enrichment of siRNA aligned with TE was observed in the inoculated samples. In addition, an increase in 24-nt siRNA mapping to genes was observed, which was correlated with an increase in methylation of the coding regions and a subsequent reduction in transcription.

Conclusion: Our results show that maize has RNA-based silencing mechanisms that can trigger specific responses when plants interact with beneficial endophytic diazotrophic bacteria. Our findings suggest important roles for sRNA regulation in maize, and probably in other plants, during association with diazotrophic bacteria, emphasizing the up-regulation of Cu-miRNA.
\end{abstract}

Keywords: Herbaspirillum seropedicae, miRNA, siRNA, Azospirillum brasilense, Epigenetics

\section{Background}

Plants have a complex mechanism of gene expression regulation that influences their development, adaptation and response to biotic and abiotic interactions. One of these mechanisms involves sRNA and can act by silencing genes at a transcriptional or post-transcription level $[1,2]$. In plants, sRNA is 20 to 24 nucleotides (nt) in length, and can be divided into two categories: microRNA (miRNA)

\footnotetext{
* Correspondence: paulof@bioqmed.ufrj.br

${ }^{\dagger}$ Equal contributors

'Laboratório de Biologia Molecular de Plantas, Instituto de Bioquímica Médica Leopoldo de Meis, Universidade Federal do Rio de Janeiro, Cidade Universitária, Avenida Carlos Chagas Filho, 373, CCS, BI.L-29ss, Rio de Janeiro RJ 21941-599, Brazil

Full list of author information is available at the end of the article
}

and small interfering RNA (siRNA), both produced by RNase III-like enzymes called DCLs, or DICER-like enzymes [3,4]. The type of precursor molecules and the enzymes involved in their biogenesis and function can differentiate these sRNA classes [5].

MiRNA is a class of sRNA derived from singlestranded precursors with self-complementary regions, forming a hairpin structure that is processed by DCL, particularly DCL1, together with a dsRNA-binding protein, HYPONASTIC LEAVES 1 - HYL1 [6]. After cleavage, a miRNA/miRNA* duplex is produced and one strand is incorporated into an RNA-induced silencing complex (RISC), where the miRNA associates with an Argonaute protein, most frequently the AGO1, guiding 
the control of target expression [7]. MiRNA can regulate their target by cleavage of messenger RNA, translational repression or transcriptional inhibition [8-10]. MiRNA is the best-characterized class of plant sRNA and they are highly conserved among related plant species [11]. Despite conservation of miRNA, a recent study has shown that new miRNA can be gained and old ones can be lost, with a rate of birth and death of the Arabidopsis miRNA genes around one per 1.2-3.3 million years [12]. Accordingly, the miRNA class can be divided into conserved families and species-specific miRNA. In contrast, siRNA is processed from longer double-strand RNA and can be divided into natural antisense transcript siRNA (nat-siRNA), secondary siRNA, like ta-siRNA whose precursor depends on cleavage of miRNA targets, and heterochromatic siRNA (hc-siRNA) produced from intergenic or repetitive regions [5]. At least three RNA-dependent RNA polymerases (RDR1, RDR2 and RDR6) are needed to form siRNA precursors [13-15]. Like miRNA, the precursor of siRNA is processed by DCL and loaded into a RISC complex containing AGO that guides target regulation [5,7]. However, specific members of the DCL and AGO family of proteins are required in the biogenesis of each different type of siRNA. For instance, RDR2 and DCL3 are preferentially used in the biogenesis of hc-siRNA originating from repetitive regions, and AGO4 is required for its function [16-18]. Repeatassociated siRNA is involved in silencing transposons and other repeat elements by methylation of DNA [19], resulting in epigenetic modifications that mediate gene silencing [20].

Small RNA has been implicated in the interaction between leguminous plants and nitrogen-fixing bacteria $[21,22]$. Gramineous plants also establish association with endophytic diazotrophic bacteria, which colonize intercellular spaces and vascular tissues of plants without causing damage to the host plant [23-25]. However, the role of sRNA in the grass-diazotrophic bacteria interaction has not been described. Maize is one of the world's most widely cultivated crops, valuable not only for human and animal consumption, but also for ethanol production [26]. Previous studies showed that maize interacts with endophytic diazotrophic bacteria, including Herbaspirillum spp. and Azospirillum spp. [27,28]. Furthermore, inoculation with diazotrophic bacteria increases maize productivity, demonstrating the benefits of these bacteria for the plant [29]. In addition to its economic importance and the successful interaction with diazotrophic bacteria, maize has several advantages as a grass-model for the analysis of plant-diazotrophic bacteria association by sRNA regulation: its genome is sequenced to a high quality [30]; recent studies have shown that maize sRNA is regulated in response to changes in the environment; and a strong epigenetic regulation occurs in maize due to the high abundance of transposable elements (TE) in the genome [31-33].

In order to understand the roles of sRNA in maize during the interaction with endophytic diazotrophic bacteria, sRNA libraries from maize hybrids (Zea mays UENF 506-8) inoculated with $H$. seropedicae were constructed and sequenced. The analysis uncovered a dynamic regulation of known and novel miRNA in plants inoculated with $H$. seropedicae. Expression analysis in biological replicas and in plants inoculated with another diazotrophic bacteria, $A$. brasilense, showed that the expression of four copper-regulated miRNAs increased in the presence of the bacteria. Targets of that miRNA are involved in copper homeostasis and in defense pathways against pathogenic microorganisms, suggesting that maize colonization by diazotrophic bacteria is facilitated by the attenuation of defense mechanisms. Also, our analysis identified novel miRNA mapping to transposable elements (TE). Additional analysis identified siRNA that matched small regions close to either the $5^{\prime}$ or $3^{\prime}$ ends of coding DNA sequences (CDSs). A reduction in the transcript levels of the corresponding CDS was verified. Finally, an increase in GC and GHC methylation was observed in the same region, suggesting an epigenetic regulation in response to diazotrophic bacteria inoculation. Our findings suggest important roles for sRNA regulation in maize during association with beneficial endophytic diazotrophic bacteria and could assist breeding programs to develop maize or other grasses more efficiently in association with diazotrophic bacteria, which would result in an improvement of crop production.

\section{Results}

\section{Maize inoculation with diazotrophic bacteria}

Diazotrophic bacteria, such as Azospirillum spp. and Herbaspirillum spp., have been linked with $\mathrm{N}_{2}$ fixation in association with agriculturally important grasses, such as maize, sugarcane and rice $[23,27,34]$. To understand the regulation of small non-coding RNA in response to association with diazotrophic bacteria, an experiment was carried out with maize plants grown in hydroponic culture and inoculated with Azospirillum brasilense (BR11005) and Herbaspirillum seropedicae (HRC54) (Figure 1A). $H$. seropedicae survives poorly in the soil, being considered an obligate endophyte [23]. In maize, these bacteria are isolated from roots, stems and leaves [27]. On the other hand, studies have shown that, depending on the $\mathrm{A}$. brasilense strain, these bacteria can survive in the soil, colonizing the root surface, or live within inoculated plants, being considered a facultative endophyte $[24,35]$. In the present work, the colonization was confirmed by the most probable number method, which counts colony-formation units (CFU) per g of fresh weigh, using plants three and seven days after inoculation (Figure 1B). Both species of 

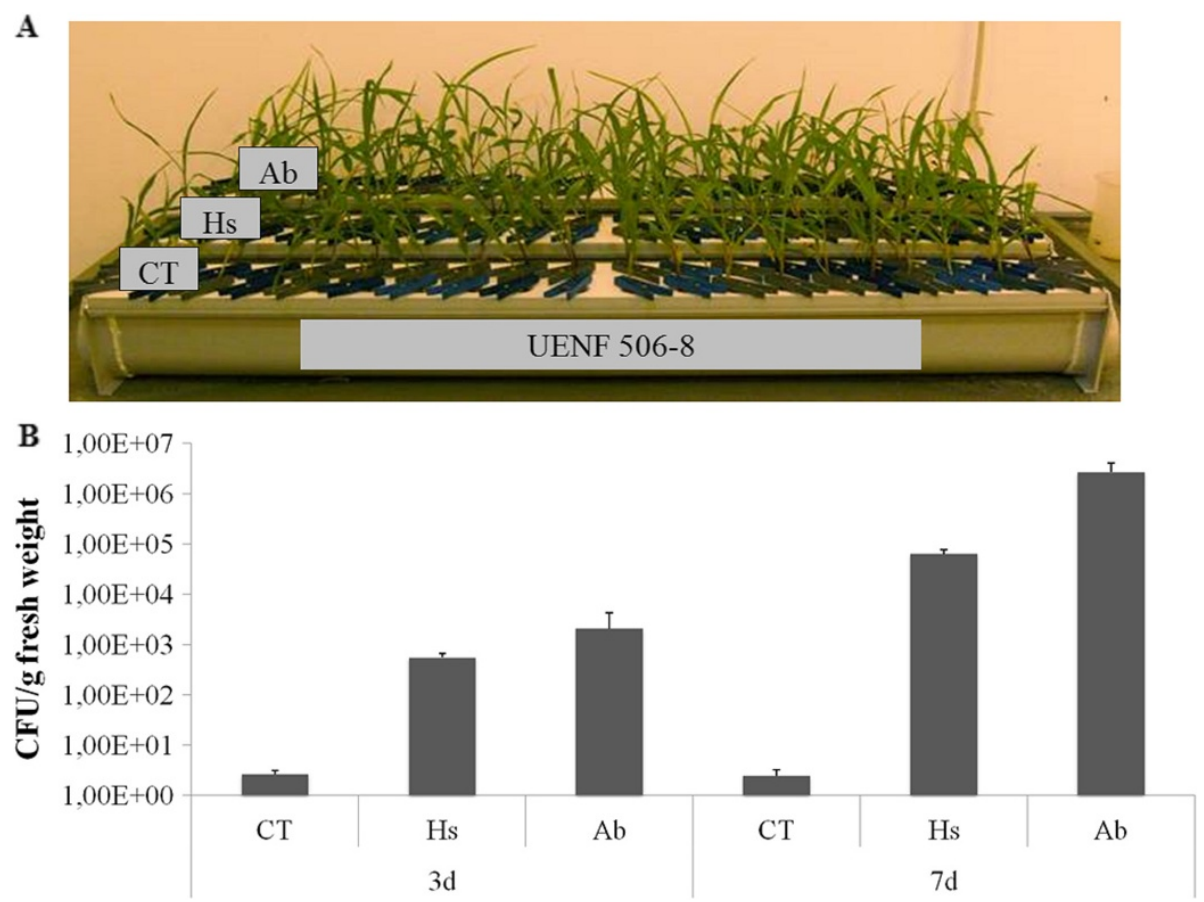

Figure 1 Maize inoculated with diazotrophic bacteria. (A) Hydroponic experiment. (B) Measurement of colonization levels in maize during the experiment. Two biological replicates were used for each treatment. The error bars represent the standard deviation. CT: mock sample; Hs: inoculation with $\mathrm{H}$. seropedicae; Ab: inoculation with Azospirillum brasilense; d: days after inoculation.

bacteria were more abundant in inoculated plants compared with the mock treatment, and there was an increase in bacterial numbers seven days after inoculation. Previous studies showed that seven days after inoculation most species of endophytic bacteria have established themselves inside the plant $[36,37]$. Therefore, further analyses were done using samples of plants harvested seven days after inoculation.

\section{Computational identification of sRNA from library data}

Small-RNA libraries prepared from control plants and plants inoculated with $H$. seropedicae were sequenced by Illumina SBS technology, providing altogether 8,629,734 raw reads. The bioinformatics pipeline used in the sRNA analysis is shown in Figure 2A. First, low-quality sequences and adapter sequences were removed; next, sequences ranging from 18 to 26 nucleotides (nt) were selected. After these steps, 4,478,875 redundant filtered reads (corresponding to 2,147,930 non-redundant sequences) from the two libraries were used for sRNA analysis. Their size distribution is shown in Figure 2B. A peak of 24-nt species was observed in the distribution of redundant reads (44\% in control library - CT; $45 \%$ in inoculated library - Hs) and non-redundant reads (54\% and $55 \%$ in CT and Hs, respectively), followed by sRNA with 22,23 and $21 \mathrm{nt}$ in length.

Filtered reads allowed the identification of two classes of sRNA: miRNA and siRNA (Table 1). Using Blastn against the B73 genome (B73 RefGen_v2) and allowing one mismatch, a total of 244 and 308 miRNA sequences were identified in control and inoculated libraries, respectively. From these reads, a search in the miRBase database, release 19, identified 237 and 295 known miRNAs in control and inoculated libraries, respectively. The other miRNAs were classified as putative novel miRNA. Eighteen novel miRNA candidates (7 in CT and 11 in Hs) were identified using the miRCat pipeline, based on the presence of mature miRNA and miRNA* sequences in the same library. The remaining reads - 750,691 in CT and 1,396,687 in Hswere classified as siRNA candidates (Table 1). Additional analysis of these sequences showed a larger number of non-redundant sequences in the inoculated library.

\section{Changes in abundance of known maize miRNA during association with endophytic diazotrophic bacteria}

The known miRNA identified were classified in 25 miRNA families, previously identified in maize or other plants. Next, the abundance of the different miRNA families was inferred from the sum of the abundance of each member and reads were normalized to compare the expression in both libraries. The results showed a dynamic miRNA regulation in response to association with diazotrophic bacteria (Table 2). While $80 \%$ of these miRNA families were identified in both libraries, miR172, miR397, miR529 and miR827 were found only in the 


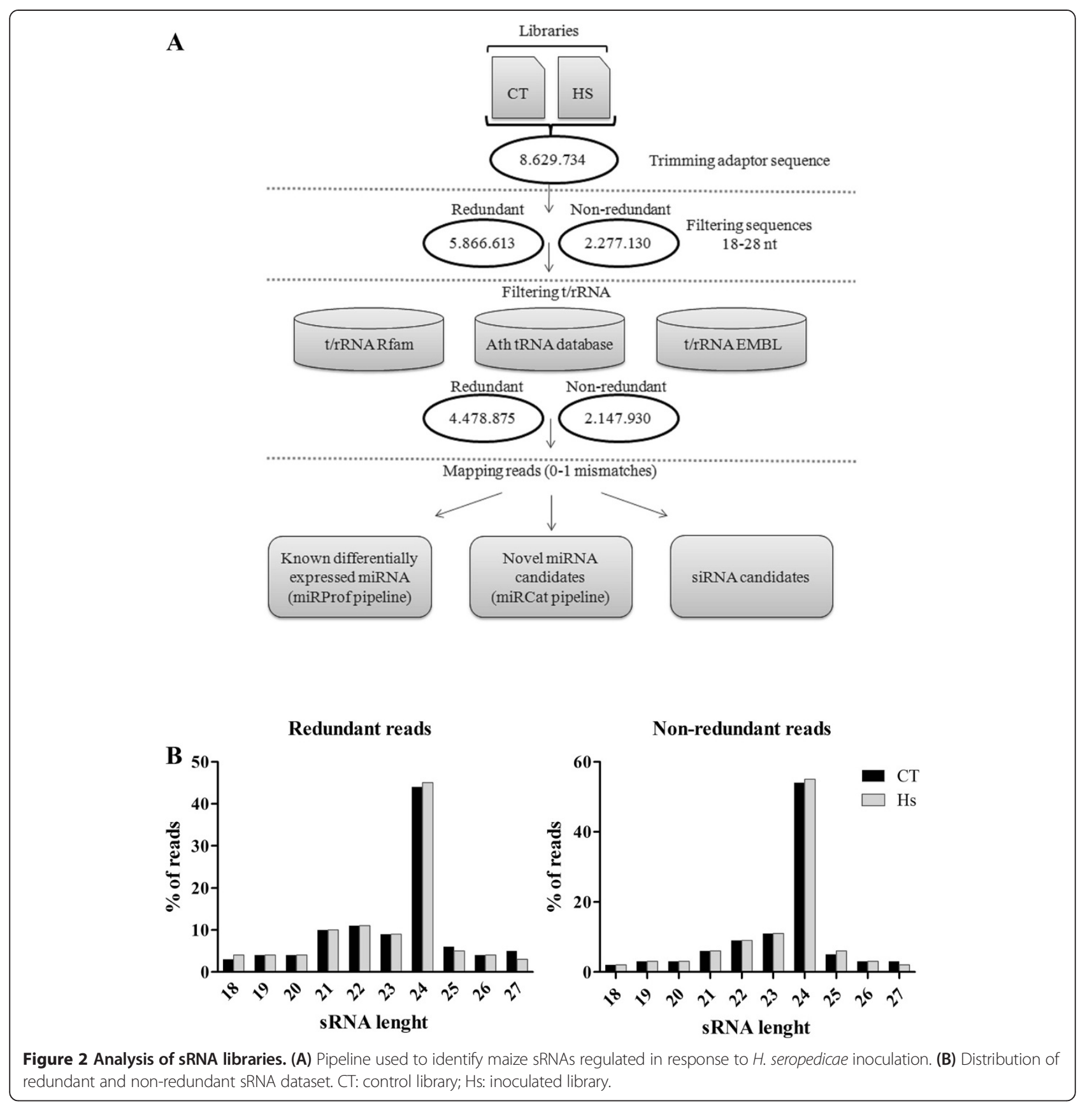

inoculated library, and miR3630 was present only in the control library. The most abundant family was miR159, followed by miR319, miR168 and miR156 (Table 2). The ratio of normalized reads in the inoculated and the control libraries for each miRNA family showed that most of these miRNA families were upregulated. The miR398 and miR408 families were the most up-regulated, showing ratios of 13.24 and 9.32, respectively. This result suggests that these miRNAs may have an important role in the maize response to the association with $H$. seropedicae.
To confirm the miRNA regulation, two more libraries were constructed and sequenced using biological replicates (experiment B) and analyzed as above. These libraries, denominated CTb and Hsb, had 5,137,415 and 2,159,935 non-redundant reads filtered, respectively. The patterns of differential expression of 25 miRNA families identified are available in Additional file 1: Table S1. Comparison between the results from libraries in experiments A and B showed that 15 miRNAs shared the same regulation profile, while 10 miRNAs had contrasting profiles. Interestingly, miR398 and miR408 were up-regulated in both analyses. 
Table 1 Summary of results obtained from bioinformatics analysis of each small RNA library

\begin{tabular}{ccc}
\hline Description & CT & Hs \\
\hline Filtered reads $^{\mathrm{a}}$ & 750935 & 1396995 \\
miRNA & 244 & 308 \\
Conserved miRNA $^{\mathrm{b}}$ & 237 & 295 \\
Novel miRNA $^{c}$ & 7 & 11 \\
siRNA candidate & 750691 & 1396687
\end{tabular}

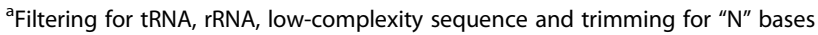
and $3^{\prime}$ adapters.

${ }^{b}$ Known miRNAs deposited at miRBase database.

CmiRNAs class I detected by miRCat pipeline.

Overall information of filtered reads, number of miRNAs detected, known

miRNAs, novel miRNAs and siRNAs using data from libraries experiment A.

\section{Cu-miRNAs are up-regulated in response to diazotrophic bacteria}

In order to understand the biological mechanisms triggered by miRNA in response to the association with diazotrophic bacteria, we identified the targets of regulated

Table 2 Differential expression of conserved miRNAs

\begin{tabular}{|c|c|c|c|c|}
\hline miRNA & CT & $\mathrm{Hs}$ & $\log 2(\mathrm{Hs} / \mathrm{CT})$ & $p$-value \\
\hline miR156 & 945.57 & 1309.01 & 0.47 & 0.000000 \\
\hline miR159 & 51822.95 & 59294.59 & 0.19 & 0.000000 \\
\hline miR160 & 119.67 & 28.49 & -2.07 & 0.000000 \\
\hline miR162 & 25.12 & 35.95 & 0.52 & 0.246230 \\
\hline miR164 & 118.20 & 114.62 & -0.04 & 0.837848 \\
\hline miR166 & 645.64 & 1033.64 & 0.68 & 0.000000 \\
\hline miR167 & 234.91 & 220.43 & -0.09 & 0.524589 \\
\hline miR168 & 1501.09 & 1526.72 & 0.02 & 0.664597 \\
\hline miR169 & 76.83 & 35.27 & -1.12 & 0.000117 \\
\hline miR171 & 97.51 & 183.13 & 0.91 & 0.000002 \\
\hline miR172 & - & 13.56 & - & 0.000977 \\
\hline miR319 & 1886.70 & 3144.33 & 0.74 & 0.000000 \\
\hline miR3630 & 29.55 & - & - & 0.000000 \\
\hline miR390 & 32.50 & 25.09 & -0.37 & 0.329586 \\
\hline miR393 & 59.10 & 25.09 & -1.24 & 0.000196 \\
\hline miR394 & 17.73 & 19.67 & 0.15 & 0.867164 \\
\hline miR396 & 463.92 & 693.84 & 0.58 & 0.000000 \\
\hline miR397 & - & 21.03 & - & 0.000015 \\
\hline miR398 & 19.21 & 254.34 & 3.73 & 0.000000 \\
\hline miR408 & 91.60 & 853.91 & 3.22 & 0.000000 \\
\hline miR444 & 53.19 & 74.61 & 0.49 & 0.089931 \\
\hline miR528 & 132.97 & 214.32 & 0.69 & 0.000037 \\
\hline miR529 & - & 8.14 & - & 0.023690 \\
\hline miR827 & - & 13.56 & - & 0.000977 \\
\hline miR858 & 90.12 & 75.28 & -0.26 & 0.285608 \\
\hline
\end{tabular}

The number of reads found in each library from experiment $\mathrm{A}$ was normalized per million, and the $\log _{2}(\mathrm{Hs} / \mathrm{CT})$ was calculated. CT: control library, $\mathrm{Hs}$ : inoculated library. The Fisher exact test was performed with Bonferroni correction.
miRNA. Using psRNA target [38], 536 unique target genes were detected in the maize genome v.2 (Additional file 2: Table S2). An ontology (GO) of the targets was constructed using AgriGO [39]. The results showed a figure with a hierarchical organization with three arms: one for transcription factor activity, one for laccase activity, and one for copper ion binding, respectively (Figure 3). In one of the arms of the figure, we observe transcription factors which are the major targets of conserved miRNA; on the other two arms of the figure, both classes are related to copper metabolism [40].

Accordingly, miR398 and miR408, the two miRNAs with sharply contrasting expression profiles in the inoculated versus the control libraries, are known as copperregulated small RNA molecules, or Cu-miRNA [41]. Moreover, miR397 and miR528 are also classified as $\mathrm{Cu}$ miRNA because they regulate proteins involved in copper homeostasis. The expression analysis showed that these four maize miRNAs were up-regulated in response to association with $H$. seropedicae (Figure 4A). Given the coordinated expression, we propose a hypothetical model for the regulation of endophytic bacteria colonization in maize: in the presence of endophytic bacteria, $\mathrm{Cu}$-miRNAs are up-regulated, and their targets, $\mathrm{Cu}$ protein, are down-regulated, leading to an attenuation of defense mechanisms and consequently facilitation of colonization (Figure 4B).

In order to confirm the model, the expression profiles of the $\mathrm{Cu}$-miRNAs were analyzed by stem-loop qRTPCR using samples from two independent experiments. Plants were harvested seven days after inoculation with either H. seropedicae or A. brasilense. The results confirmed an increase in expression of miR397, miR398, miR408 and miR528 in plants inoculated with H. seropedicae (Figure 5). Moreover, three of the four miRNAs were also up-regulated in samples inoculated with $A$. brasilense.

To ascertain whether the putative targets of $\mathrm{Cu}$-miRNA had inverse expression profile, their mRNA levels were measured by qRT-PCR, using the same samples (Figure 6). Basically, the results showed that the targets were downregulated in samples inoculated with endophytic bacteria. The one exception was the putative target of miR528; in plants inoculated with $A$. brasilense an increase in mRNA accumulation was observed, suggesting that in this situation, this mRNA is either not a target of miR528, or there is an additional layer of transcriptional control of its expression. Altogether, the results support the proposed model for the regulatory pathways triggered in maize in response to endophytic diazotrophic bacteria.

\section{Identification of novel maize miRNA}

Next, a search for novel miRNA candidates was carried out using the miRCat pipeline mapped to the Zea mays genome v.2 and a Blast-n search against the miRBase 


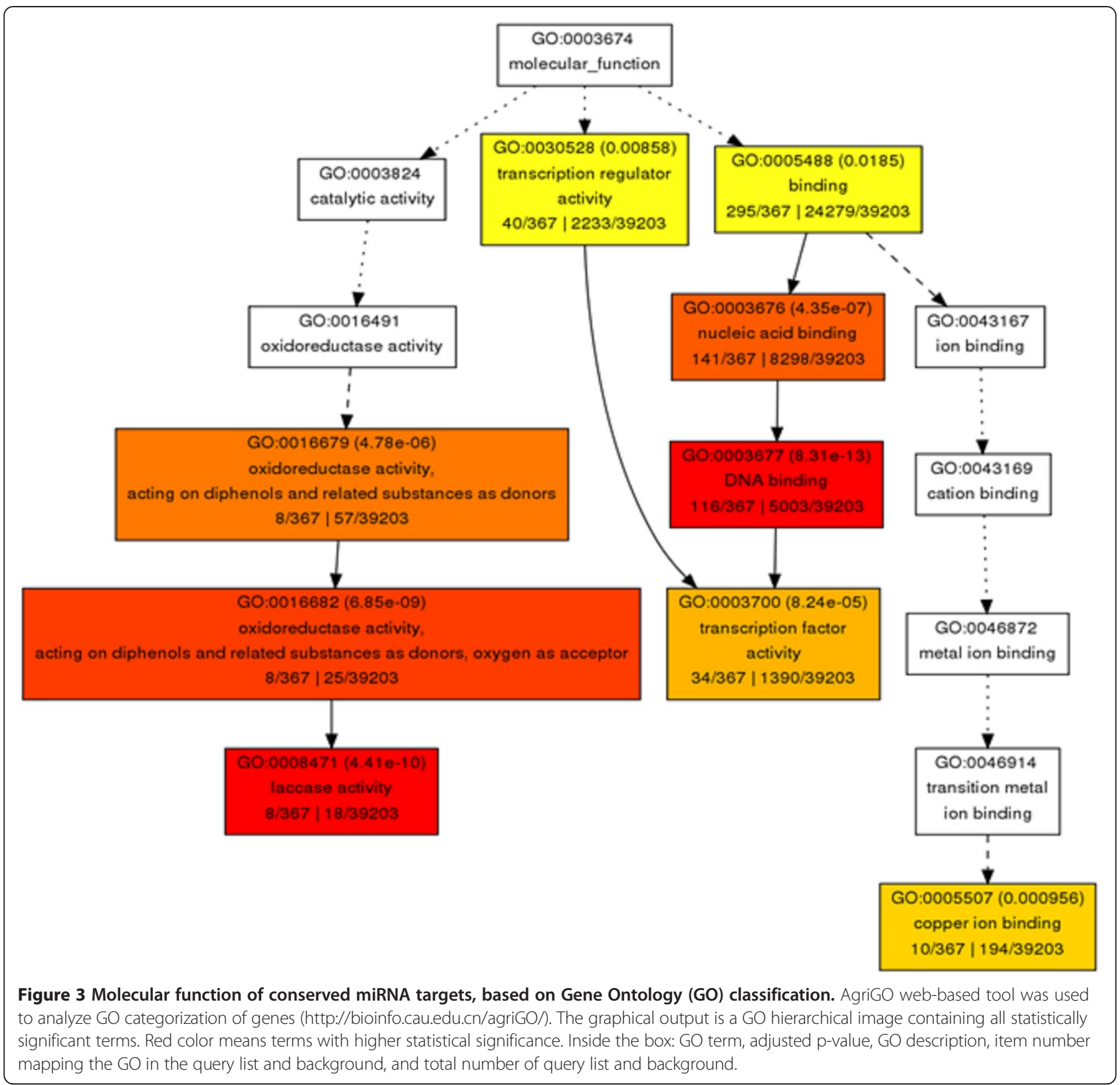

database, release 19. MiRNA sequences that showed no hits to the miRBase database and had a precursor characteristic of miRNA were selected. Based on the criteria for miRNA annotation established by the plant smallRNA research community [42,43], we selected only miRNA precursors that exhibited miRNA and miRNA* sequences in the same libraries (Class I). Hence, 18 bona fide precursors with miRNA/miRNA* complementarity were found, corresponding to 15 novel mature miRNA sequences (Table 3). These miRNAs were denominated Zma_miR_Seq01 to Zma_miR_Seq15. The length of novel miRNA precursors ranged from 75 to $232 \mathrm{nt}$ and their structure with the position of miRNA/miRNA* highlighted is available in Additional file 3: Figure S3. The precursor fold-back structures have an MFE (Minimum Free Energy) ranging from -23.9 to $-110.7 \mathrm{kcal} /$ mol, and more than $77 \%$ had an MFEI (Minimum Fold Energy Index) value greater than 0.7 (Table 3).

In addition to the precursor analysis, the length and the abundance of new mature miRNA was also examined. The majority of the novel miRNAs are $24 \mathrm{nt}$ in length ( 9 out 15 sequences), four were of $21 \mathrm{nt}$ and two were of 22 nt. To compare the expression of novel miRNA, we used the same approach described for expression analysis of known miRNA. Eleven new miRNAs were identified in the inoculated sample, three of which were 


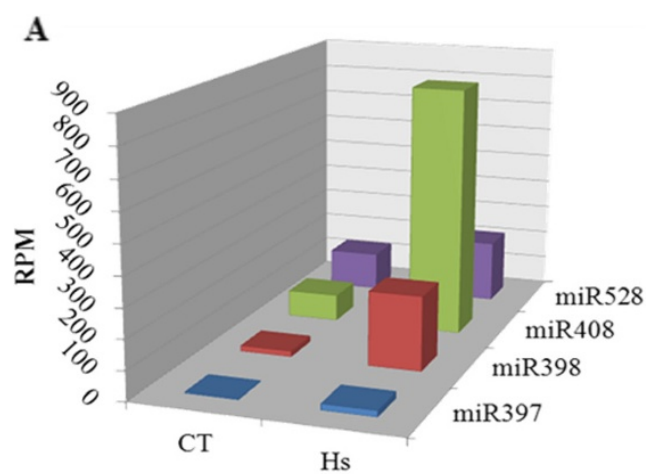

sRNA library
B

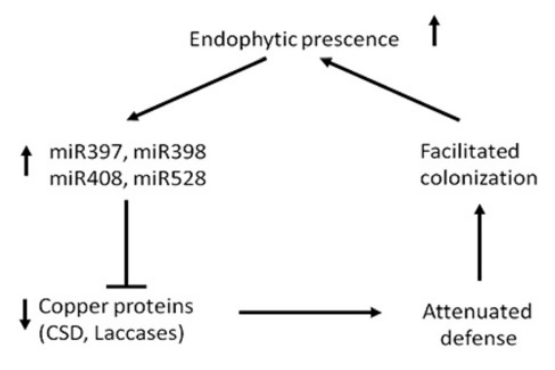

Figure 4 Regulation of four Cu-miRNAs in response to endophytic association. (A) Distribution of miRNA profile expression identified by bioinformatics analysis. CT: control library; Hs: H. seropedicae inoculated library; RPM: reads per million. (B) Putative pathway of regulation of miRNAs/targets involved in copper metabolism.

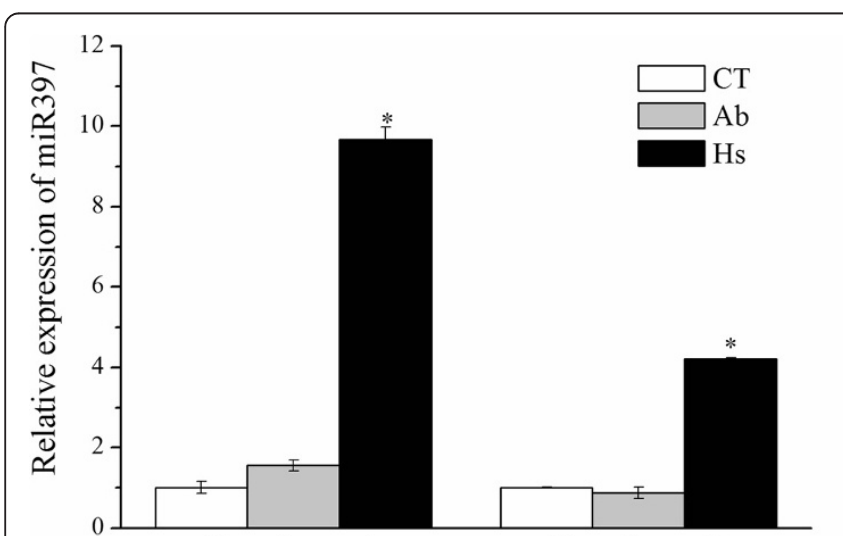

Experiment A

Experiment B

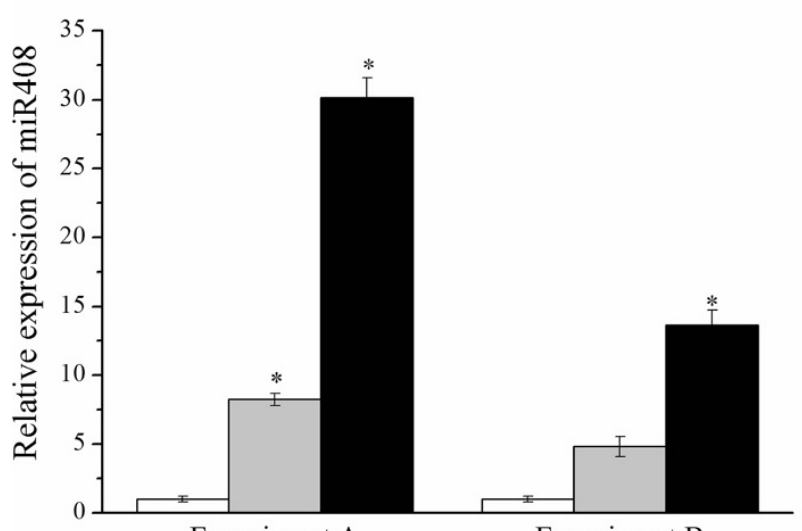

Experiment A

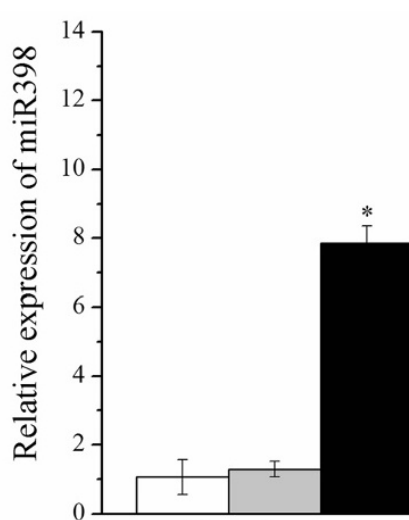

Experiment A

Experiment A
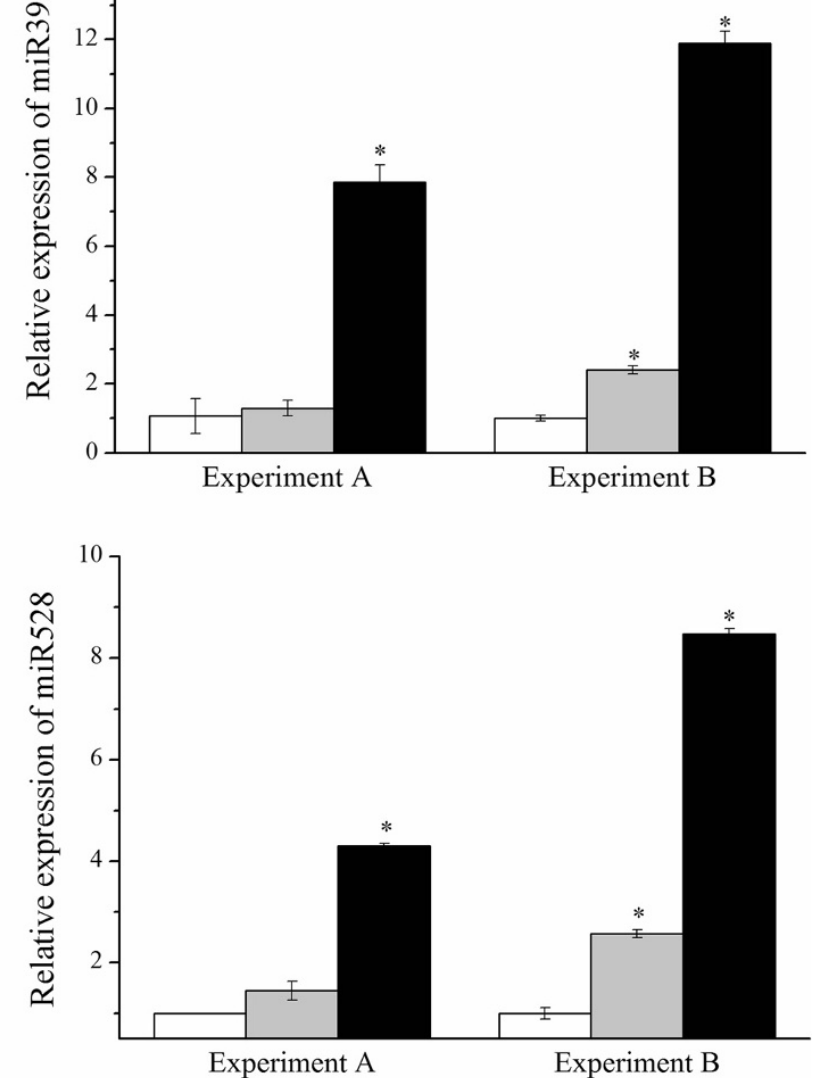

Experiment B

Experiment B

Figure 5 Expression of Cu-miRNA in plants inoculated with A. brasilense and H. seropedicae. Relative expression of miR397, miR398, miR408 and miR528 in response to inoculation with A. brasilense and H. seropedicae. Biological replicates were analyzed (Experiment A and B). The error bars represent the standard deviation between three technical replicates. *represent significant changes in miRNA expression between control and inoculated samples for each experiment ( $p$-value $<0.05$ ). 


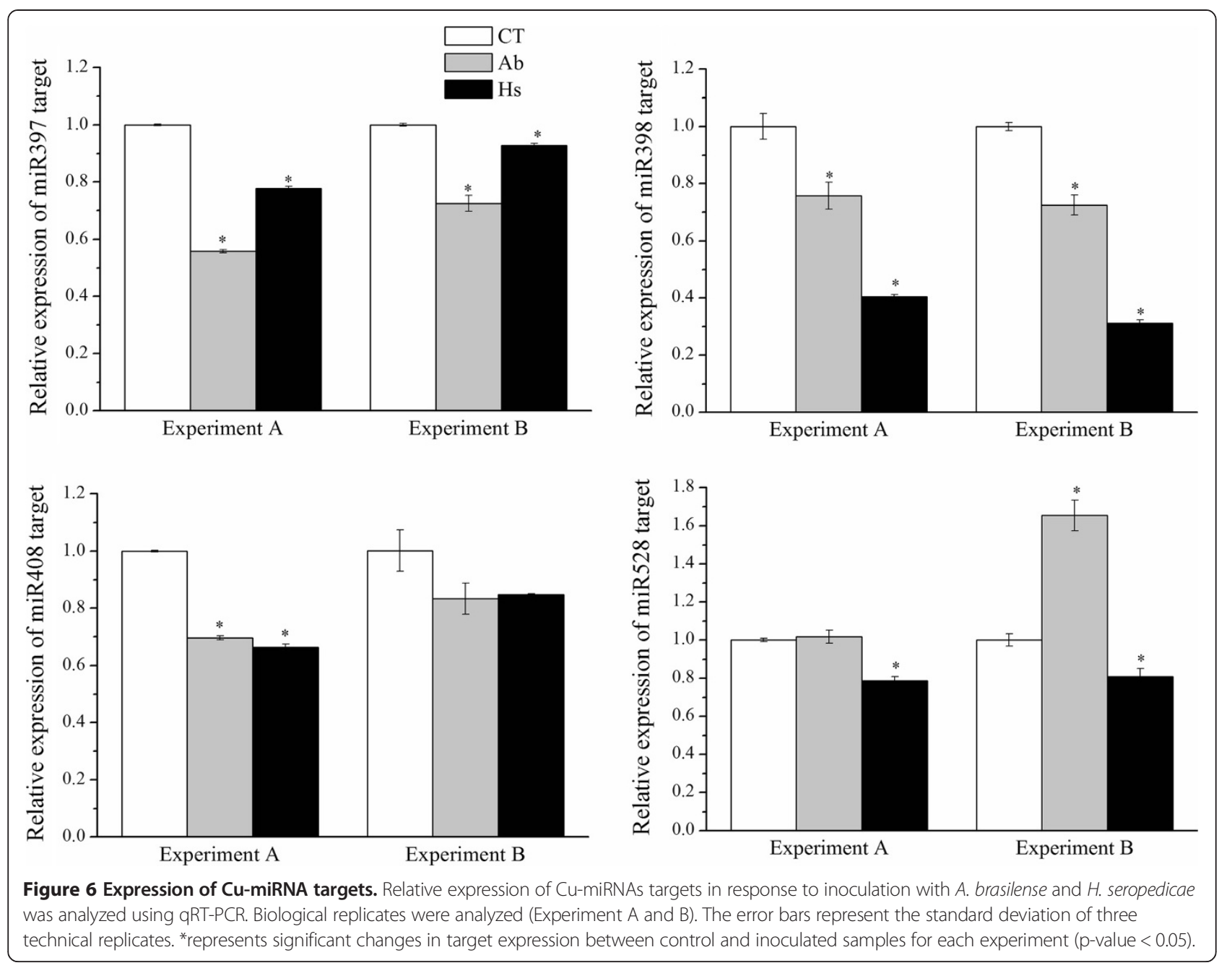

also found in the control library but at lower levels. Four novel miRNAs were exclusive to the control library (Table 3). Next, their putative targets were predicted using psRNA target. A total of 131 putative targets for the 15 mature new miRNAs were identified (Additional file 1: Table S1). However, more than $87 \%$ of the putative targets are uncharacterized genes. Therefore, the molecular function of these novel miRNAs is unknown.

In order to investigate the role of these novel miRNAs, further analyses were performed using the POPcorn website (http://popcorn.maizegdb.org/main/index.php) to map them in the maize genome v.2. The results showed the precursors of new miRNAs scattered throughout the genome (Additional file 4: Figure S4). Next, also using the POPcorn website, the precursors were compared with TEs from the Maize Transposable Elements database. In this analysis, seven of the new miRNAs aligned with different classes of maize DNA transposon, among them PIF/Harbinger, CACTA, Mutator and hAT (Table 4).
siRNA production derived from repeats and CDSs

In order to find repeat-associated siRNA in maize sRNA libraries, we aligned the siRNA candidates (Table 1) in the maize repeat database (Repbase, v.18) using the Bowtie alignment and allowing three mismatches. Only the best hits of aligned siRNA from each library were selected for further analysis, giving a total of 117,935 and 222,432 siRNAs from control and inoculated libraries, respectively. These siRNAs aligned with different classes of TE, among them 14 classes of DNA transposon, five classes of retrotransposon, rRNA, satellite, SINE/tRNA, Knob, centromere, telomere and a number of unclassified repeats (Figure 7A). Approximately eight percent of the siRNAs in each library came from a DNA transposon, and approximately 32\% were from a retrotransposon, especially Copia and Gypsy. In all classes, more siRNA were identified in the inoculated than in the control library. Nevertheless, a small fraction of the total siRNA was present in both libraries. For instance, 3,307 siRNAs from Copia were identified in both libraries, 
Table 3 New miRNAs identified

\begin{tabular}{|c|c|c|c|c|c|c|c|c|}
\hline miRNA ID & $\begin{array}{c}\text { Length of } \\
\text { hairpin precursor }\end{array}$ & MFE & MFEI $^{\mathrm{a}}$ & Randfold p-value & Sequence & sRNA length & RPM - CT & RPM - Hs \\
\hline Zma_miR_Seq01 & 169 & -42.5 & 0.61 & 0.029703 & AAAATTTAGAGGACGTTGCTGGAG & 24 & - & 10.34 \\
\hline Zma_miR_Seq02 & 141 & -84.8 & 1.15 & 0.009901 & AAACCGTCGGAGATAGCTTATGTC & 24 & - & 8.86 \\
\hline Zma_miR_Seq03 & 128 & -76.7 & 1.08 & 0.009901 & AACCTATGTCCGACGGTITAGGC & 24 & - & 7.39 \\
\hline Zma_miR_Seq04 & 79 & -26.4 & 0.52 & 0.09901 & ACGTCTATGGTTAGATCACGCGGC & 24 & - & 8.86 \\
\hline Zma_miR_Seq05 & 75 & -23.9 & 0.70 & 0.049505 & ATAACTGTAGTGCATTAAAGCGGG & 24 & 4.07 & 7.39 \\
\hline Zma_miR_Seq06 & 173 & -60.52 & 0.85 & 0.009901 & ATCCATATGGACTGGGAGGAAAGC & 24 & - & 44.32 \\
\hline Zma_miR_Seq07a & 104 & -58.3 & 0.80 & 0.009901 & CCCGCCGGCGAGCGCTITCCT & 21 & - & 13.30 \\
\hline Zma_miR_Seq07b & 104 & -58.3 & 0.80 & 0.019802 & CCCGCCGGCGAGCGCTTTCCT & 21 & - & 13.30 \\
\hline Zma_miR_Seq08 & 170 & -91.5 & 0.92 & 0.009901 & CGGCGGGGGCGAACTGAGAAC & 21 & 21.70 & 143.31 \\
\hline Zma_miR_Seq09a & 161 & -64.2 & 0.84 & 0.009901 & CGTGGTATTGTTTCGGCTCATG & 22 & 11.53 & 125.58 \\
\hline Zma_miR_Seq09b & 123 & -57.4 & 0.94 & 0.009901 & CGTGGTATTGTTTCGGCTCATG & 22 & 11.53 & 125.58 \\
\hline Zma_miR_Seq09c & 123 & -57.4 & 0.94 & 0.009901 & CGTGGTATTGTITCGGCTCATG & 22 & 11.53 & 125.58 \\
\hline Zma_miR_Seq10 & 114 & -31.3 & 0.68 & 0.059406 & TCCTTGTTGGACAGATAAAGGAGC & 24 & - & 7.39 \\
\hline Zma_miR_Seq11 & 85 & -45.5 & 1.17 & 0.009901 & TTGTTGGTCTATTCGGGTTITCGA & 24 & - & 7.39 \\
\hline Zma_miR_Seq12 & 143 & -57.8 & 0.81 & 0.009901 & CATGAACCGAGCGAGCTAGCGAGC & 24 & 14.92 & - \\
\hline Zma_miR_Seq13 & 232 & -110.7 & 0.75 & 0.009901 & GGCGGACTGGGAACACATGGG & 21 & 7.46 & - \\
\hline Zma_miR_Seq14 & 152 & -103.3 & 1.45 & 0.009901 & TTGGGAGCCACAAAACTGAAG & 21 & 3.39 & - \\
\hline Zma_miR_Seq15 & 179 & -84 & 1.00 & 0.009901 & TTITGTTGGTGGTCATTTAACC & 22 & 14.24 & - \\
\hline
\end{tabular}

${ }^{a}$ minimal folding free energy index (MFEl) was calculated according to Zhang et al. [99].

$\mathrm{CT}$ : control library, Hs: Inoculated library, RPM: reads per million, MFE: Minimum Free Energy.

while 13,154 and 28,566 were exclusive to the control and inoculated library, respectively. Figure $7 \mathrm{~B}$ shows the number of exclusive and shared siRNA from Copia and Gypsy. These siRNA were analyzed for size distribution, and the majority was $24 \mathrm{nt}$ in length, with a smaller population of $22 \mathrm{nt}$ (Figure 7C).

Additional analyses were performed to classify siRNA with homology to CDSs. A total of 237 and 456 CDSs aligned with more than 50 unique siRNAs from control and inoculated libraries, respectively. Among these, five CDSs had more than 1,000 siRNA sequences from the inoculated library aligned with them. Two CDSs that showed the highest amounts of siRNA aligned, GRMZM2G03 7875_T03 and GRMZM2G487629_T02, were selected to

Table 4 Novel miRNAs mapped at Transposable Elements

\begin{tabular}{lc}
\hline miRNA ID & TE class \\
\hline Zma_miR_Seq01 & PIF/Harbinger \\
Zma_miR_Seq02 & CACTA \\
Zma_miR_Seq03 & CACTA \\
Zma_miR_Seq05 & Mutator \\
Zma_miR_Seq06 & PIF/Harbinger \\
Zma_miR_Seq11 & hAT \\
Zma_miR_Seq12 & hAT \\
\hline
\end{tabular}

Novel miRNA precursors were mapped against TEs from the Maize Transposable Elements Database (http://maizetedb.org/ maize/). carry out further analyses. GRMZM2G037875_T03 aligned with 721 and 1545 unique siRNA sequences in control and inoculated libraries, respectively. This difference was statistically significant. In each library, $71 \%$ of the siRNAs were 24-nt species. Almost all siRNAs mapped onto the fourth exon of GRMZM2G037875_T03 (Figure 8). Interestingly, this splice variant of the GRMZM2G037875 gene had an exclusive region at the 3 '-end on the fourth exon where the siRNA mapped. Because $24 \mathrm{nt}$ can trigger DNA methylation, the methylation profiles of these CDSs were investigated [44]. The results show that the region where the siRNA mapped was highly methylated in CG and CHG sites (Figure 8). In order to verify the expression of the CDSs, a dataset of mRNAseq obtained from the same biological samples (Carvalho et al., personal communication) was examined. A total of 249.6 and 170.8 normalized reads from the control transcriptome library and 192.9 and 135.6 reads from the inoculated library mapped onto GRMZM2G037875_T03, with significantly more reads mapped at the 3 '-end on the fourth exon in the control library than in the inoculated library, showing an inverse regulation to that of the siRNA. A similar analysis was performed for CDS GRMZM2G487629_T02 (Additional file 5: Figure S5), and almost all of the siRNA mapped onto the 5 '-end of these CDSs. Normalized siRNA that aligned with these CDS were 1026.72 and 1046.53 from control and inoculated libraries, respectively. Despite a 

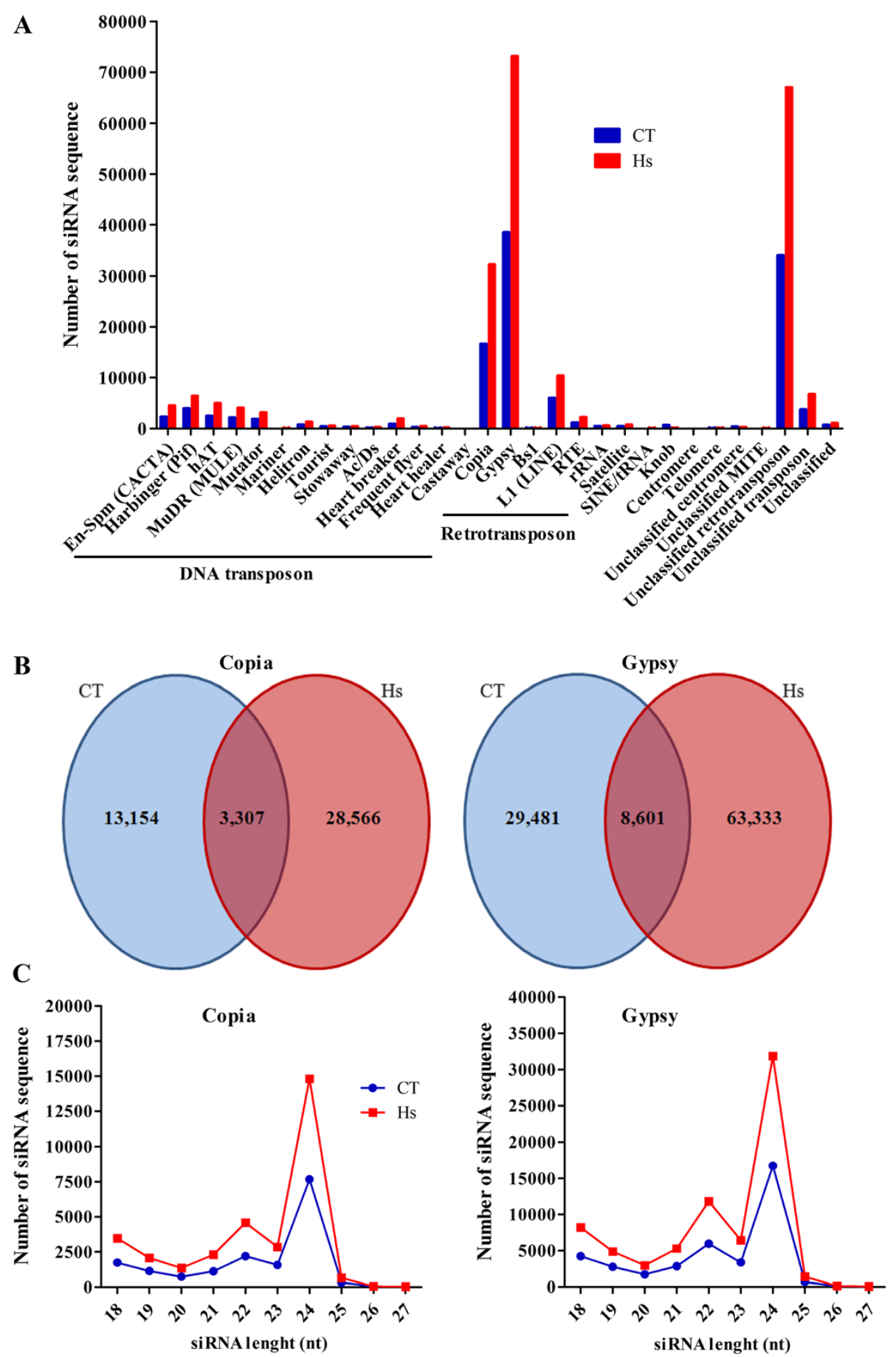

Figure 7 siRNA mapped to repeats. (A) Distribution of siRNA that aligned with the Repbase database. (B) Number of siRNA identified in each library matching Copia and Gypsy. (C) Length distribution of siRNA related with Copia and Gypsy. CT: control library; Hs: H. seropedicae inoculated library.

small increase in siRNA in the inoculated library, this difference was not significant; but the methylation analysis also revealed an enrichment of methylated sites in the same region of the siRNA peak (data not shown).

\section{Discussion}

Recently, plant sRNA regulation has been shown to play important roles in plant development, nutrition homeostasis, response of abiotic stress and the plant-microbe 


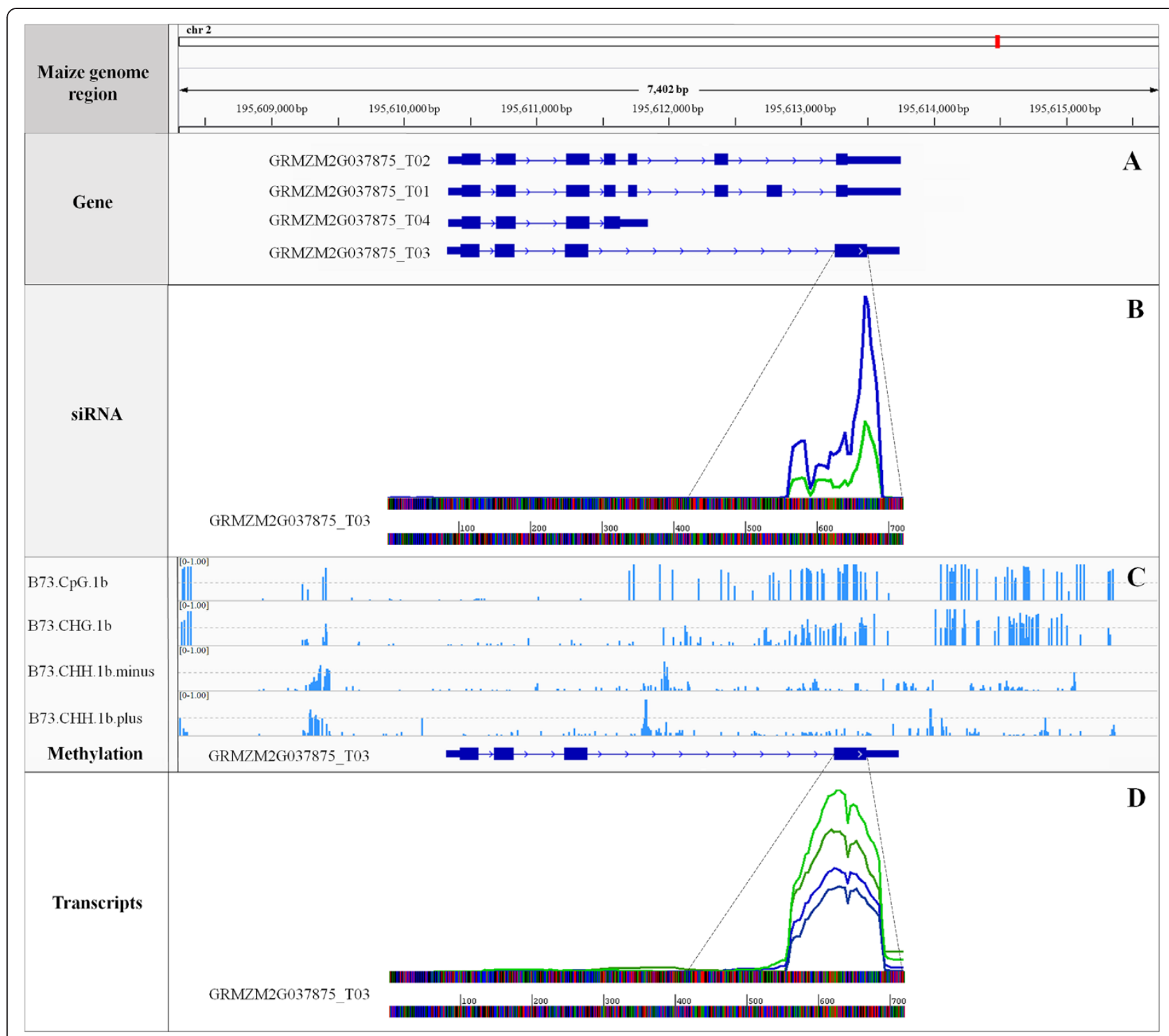

Figure 8 Analysis of siRNA, methylation profile and mRNAseq reads mapped to the sequence of a splice variant of GRMZM2G037875.

(A) Localization of GRMZM2G037875 gene in chromosome 2 and four possible splice variants from this gene (boxes represent exons, and lines are introns). (B) Position of siRNA aligned in GRMZM2G037875_T03. The two peaks, blue and green, are non-redundant siRNA sequences from inoculated and control libraries, respectively. (C) Four data tracks show methylation levels for B73 in different sequence contexts. Methylation levels are displayed on a scale from 0 to 1. (D) Position and abundance of transcripts that matched in GRMZM2G037875_T03. Blue and green indicate transcript sequences from inoculated and control libraries, respectively.

interaction, including interaction with pathogens, and in rhizobia-legume symbiosis [45-48]. One characteristic of the association of leguminous plants and rhizobia bacteria is the development of structures called root nodules, where bacteria establish and contribute to the plant with biologically fixed nitrogen [22]. Endophytic nitrogenfixing bacteria have also been isolated from gramineous plants. However, in grasses, the diazotrophic bacteria are found colonizing intercellular spaces and vascular tissues of most plant organs, without forming any particular structure $[24,49]$. Although several studies have described the benefits of grass-diazotrophic bacteria interactions and the molecular pathways involved in this association [50-52], little is known about the role played by sRNA in response to colonization by endophytic diazotrophic bacteria in grasses, like maize. One study has shown that the maize hybrid line UENF 506-8 has an efficient association with diazotrophic bacteria [53]; this hybrid, therefore, was used in the present study.

The main categories of plant regulatory sRNA are miRNA and siRNA [47]. Our analysis identified a set of maize miRNA and siRNA regulated by the association of the plant with diazotrophic bacteria. Maize sRNA libraries made from seedlings inoculated for seven days with the 
endophytic diazotrophic bacteria H. seropedicae (HRC54) and control seedlings were constructed and sequenced. The distribution profile of sequenced sRNA showed that the most abundant and most complex fraction was the sRNA of $24 \mathrm{nt}$ in length, followed by 22, 23 and $21 \mathrm{nt}$, in agreement with published reports of maize small- RNA libraries [54-56].

Based on characteristics of plant miRNA conservation, 25 miRNA families were identified in the analysis. Among the miRNA most expressed in plants inoculated with $H$. seropedicae, miR159 and miR168 were also identified as being regulated in soybean nodules [22], suggesting a role for these miRNAs in the association of diazotrophic bacteria with plants. Interestingly, these miRNAs were previously characterized as miRNA modulated in response to pathogen infection. MiR159 was up-regulated in Arabidopsis inoculated with Pseudomonas syringae [57], as well as in maize inoculated with beneficial bacteria. In contrast, the miR393 expression profile in response to diazotrophic bacterial inoculation was different from that observed in a pathogenic infection. MiR393 was the first miRNA described to be involved in the regulation of plant immunity [58]. This miRNA was induced in plants infected with Pseudomonas syringae, contributing to antibacterial resistance $[57,59]$. On the other hand, in maize inoculated with diazotrophic bacteria, a repression of miR393 was observed, suggesting that in the presence of $H$. seropedicae, the defense response through the miR393-based regulation pathway was not activated.

More recently, miR397 has been shown to be involved in nitrogen fixation-related copper homeostasis in Lotus japonicus [21]. MiR397 was classified as $\mathrm{Cu}$-miRNA, because its target is an mRNA that encodes laccase protein involved in copper homeostasis. In maize, four $\mathrm{Cu}$ miRNAs - miR397, miR398, miR408 and miR528 - were up-regulated and their targets were down-regulated in response to $H$. seropedicae inoculation. There are canonical targets described for these miRNAs and the cleavage of these targets by their respective miRNAs was previously confirmed using RACE 5' PCR [60-62]. Copper is an important micronutrient and serves as a cofactor for proteins involved in important pathways, among them photosynthesis and the metabolism of scavenging reactive oxygen species [63]. In plants, targets of other evolutionarily conserved miRNA encode genes involved in copper homeostasis, such as laccase, copper superoxide dismutase (CSD) and cupredoxin [41]. The described targets of miR397, miR408 and miR528 in maize are laccases and cupredoxins [64], important copper protein families with redox activities [65] whose domains are conserved in other enzymes [66]. More so, in maize, cupredoxins are involved in oxidative stress response signaling, mediating electron transfer or oxidation homeostasis during stress [67]. Biotic stress causes accumulation of reactive oxygen species as an early response to pathogen attack [68]. The oxidative burst can result in the direct death of pathogens, acting as a mechanism of plant defense [69]. Previous work has shown that miR408, after $14 \mathrm{~h}$, is repressed in Arabidopsis plants inoculated with the pathogenic bacteria, Pseudomonas syringae pv. Tomato, while its target was induced [70], suggesting that biotic stress can trigger down-regulation of $\mathrm{Cu}$-miRNA, increasing the steadystate of their targets, generating a burst of oxidative stress. In plants inoculated with endophytic diazotrophic bacteria, an inverse miRNA/target regulation was observed: miR397, miR408 and miR528 were induced, and their targets were repressed. These results suggest that $H$. seropedicae does not activate the early defense response against bacterial colonization in maize. A similar regulation of these miRNAs occurs in plants inoculated with A. brasilense. Furthermore, an additional role for miR408 in plant/beneficial interaction might be to reduce lignin biosynthesis as a consequence of decreased laccase activity [71], facilitating colonization by endophytic bacteria.

Copper superoxide dismutase is responsible for removing reactive $\mathrm{O}_{2}$ species (ROS), reducing oxidative stress [72]. Superoxide dismutase is the first line of defense to convert this reactive oxygen species [73]; accordingly, during pathogenesis, CSD accumulates due to the repression of miR398 expression [72,74]. In contrast, the up-regulation of miR398, and consequently, the repression of its target, suggests once more that beneficial endophytes such as $H$. seropedicae and $A$. brasilense are not recognized as pathogens by maize and therefore do not trigger defense responses such as ROS production.

A subset of miRNA is considered non-conserved if it is present only in certain plants or in closely related species [75,76]. The miR528, for instance, is an example of monocot-specific miRNA [77]. Non-conserved miRNA is the result of emerging classes of lineage-specific families, and it originated from recently evolved MIR genes [78]. Here, we have identified 18 bona fide precursors of novel miRNAs, which obey all the rules established for identification of new microRNA, including the identification of miRNA and miRNA* sequences in the same library. The majority of these new miRNAs are 24-nt species, longer than canonical 21-nt miRNA [79]. A recent study proposed that miRNA with $24 \mathrm{nt}$ is derived from precursor cleavage by DCL3 and that its biogenesis is similar to that of siRNA $[80,81]$. Because these novel miRNAs had not been identified in other plants, they probably have emerged recently as lineage-specific miRNA. The evolution of miRNA genes has been widely discussed and two hypotheses for miRNA birth have been postulated: miRNA genes could originate from inverted gene duplication [82] or randomly from repetitive elements present in the genome $[83,84]$. In support of the last model, a recent study revealed the co-localization of maize miRNA within 
TE sequences [64]. Furthermore, analysis of 163 miRNAs evolving from repetitive elements in four plants, Arabidopsis, poplar, rice and sorghum, demonstrated that a considerable number of young miRNA identified were species-specific [83]. In our study, a subset of the novel miRNA identified was characterized as repetitive elementrelated miRNA, suggesting that they are young miRNA. Although the targets of the novel miRNAs have not been determined, most of these miRNAs are induced in response to plant-diazotrophic bacteria association and their targets could play a role in the plant's interaction with diazotrophic bacteria.

More frequently in plants, the number of miRNA families related to TE is smaller than the number of miRNA families not related to TE [85]. However, TEs are highly abundant in maize, comprising more than $80 \%$ of the genome [30]. Repeat-associated siRNA has been identified in maize, especially siRNA matching retrotransposons. This corroborated data that showed that the maize genome has more retrotransposons than DNA transposons, with Gypsy being the most frequent class [86]. The majority of siRNAs derived from TE have 24 nt followed by 22-nt species. Repeat-associated siRNA is most commonly of $24 \mathrm{nt}$, and recent studies have suggested that RDR2 and DCL3 are required for the biogenesis of this siRNA class, while 24 nt guided-DNA methylation is dependent on DCL4 $[5,17,18]$. Additionally, there is evidence of other mechanisms involved in the production of siRNA from repeats, inferred from an enrichment of 22-nt siRNA that was seen in the MOP1 mutant, an ortholog of RDR2 [87]. In plants, despite the existence of many TEs, they are usually inactive. SiRNA could be a tool for controlling their own TE precursors, acting as a feedback mechanism [88]. Interestingly, TEs are activated in response to stress, including pathogen infection, mechanical stress or abiotic stress [89,90]. Accordingly, TEs are demethylated during pathogen infection in Arabidopsis, relevant because TE demethylation is thought to take part in the plant defense genes' activation [91]. On the other hand, several siRNAs from TEs were identified only in the inoculated library, suggesting that siRNA may also have an important role in TE silencing, resulting in a more efficient plant association with beneficial bacteria. Based on this, it is possible to propose that plants can sense pathogenic and beneficial microorganisms differently and trigger specific epigeneticmediated regulatory mechanisms.

It has been shown that siRNA that match proteincoding genes can regulate gene expression [17,92]. In this study, genes with a large number of siRNA aligned with their CDSs were identified, five among them with more than 1,000 unique siRNA reads. Although, these genes are classified as unknown, the abundance and complexity of the siRNAs mapping onto these genes suggest that its silencing could be important for diazotrophic bacteria association, given that more siRNAs were identified in the inoculated sample. GRMZM2G03 7875_T03 is the CDS with greatest number of unique siRNAs aligned with it. Interestingly, a hotspot of mapped siRNAs is located at the 3 '-end of the CDS, a region that is exclusive to one splice variant of GRMZM2G037875. In contrast, for another CDS, GRMZM2G487629_T02, siRNAs were aligned at the 5 '-end. According to a recent study in Arabidopsis, siRNA related to proteincoding genes can be generated by the RDR2-DCL3 pathway, but the mechanism that regulates gene expression of protein-coding genes by siRNA is not well understood [17]. One hypothesis is that the siRNA is loaded onto AGO4-containing complexes to guide methylation of target genes. Accordingly, the gene regions enriched for siRNA are also enriched in sites of CG and CHG methylation [44]. For two CDSs (GRMZM2G037875_T03 and GRMZM2G487629_T02), the results suggested that siRNA can mediate the DNA methylation. Also, the majority of maize siRNA that aligned in this CDS is $24 \mathrm{nt}$ in length, corroborating the hypothesis that 24 nt siRNA triggers DNA methylation [93]. DNA methylation at the $5^{\prime}$ or $3^{\prime}$-end has been correlated with the silencing of genes, consequently leading to the reduction of gene transcription [94,95]. Interestingly, the levels of GRMZM2G 037875_T03 transcript were reduced in transcriptome analysis of plants inoculated with $H$. seropedicae, suggesting that this splice variant was methylated by siRNA, leading to a decreased transcription. This information can help to understand the regulation of this siRNA class; however, further studies should be performed to uncover the function of the genes, in particular the role of the splice variant that is enriched in the plants inoculated with diazotrophic bacteria.

\section{Conclusions}

Relatively little is known about plant epigenome mechanisms involved in the plant response to diazotrophic bacteria. Our results show that plants may use a variety of sRNA regulation mechanisms to regulate and favor this association, and that the mechanisms activated are in contrast with the ones previously described for pathogen infection. In conclusion, our data suggest that maize, and possibly other grass species, have RNA-based silencing mechanisms that can trigger specific responses when plants interact with microorganisms to establish either a beneficial association or to fight pathogenic infection.

\section{Methods}

\section{Plant material and diazotrophic bacteria inoculation}

Maize seeds of the hybrid UENF 506-8 were surfacesterilized for 15 min with a $10 \%(\mathrm{v} / \mathrm{v})$ solution of commercial bleach containing $5.25 \%(\mathrm{w} / \mathrm{v}) \mathrm{NaCl}$, then washed 
several times with distilled water. After soaking overnight in distilled water, seeds were germinated at $25^{\circ} \mathrm{C}$ in wet paper. Seven days after germination, seedlings were transferred to a $0.5 x$ Hoagland's solution [96] in a growth chamber at $24^{\circ} \mathrm{C}$ with a $10 \mathrm{~h}$ photoperiod and left for two weeks. The Hoagland's solution was renewed every 3 or 4 days. After this period, seedlings were inoculated with two diazotrophic bacteria, A. brasilense (BR11005) and $H$. seropedicae (HRC54), as described by James et al. [97]. Suspensions $(150 \mathrm{uL})$ containing $10^{-6}$ to $10^{-7}$ diazotrophic bacteria were added to each $30 \mathrm{~mL}$ of the plant growth medium. Control plants were mock inoculated. Seven days after inoculation, whole plants were harvested, bacteria colonization was evaluated by the Most Probable Number (MNP) estimation [98], and quickly frozen in liquid nitrogen. Four experiments were performed, of which two were used for Illumina sequencing, while the other two were used to validate the sequencing analysis. Total RNA was isolated from whole plants using Trizol (Invitrogen, CA, USA) as described by the manufacturer. RNA purity was analyzed using a Thermo Scientific NanoDrop $^{\text {tw }} 2000$ c spectrophotometer and the RNA integrity was verified by electrophoresis on a $1 \%$ agarose gel.

\section{Construction and analysis of small RNA libraries}

Two sRNA libraries made from control maize hybrid (UENF 506-8) seedlings and seedlings inoculated for seven days with diazotrophic bacteria, $H$. seropedicae (HRC54) were constructed and sequenced; two biological replicas of each library were sequenced. Total RNA $(\sim 10 \mu \mathrm{g})$ from control and $H$. seropedicae inoculated plants was sent to Fasteris Life Sciences SA (Planles-Ouates, Switzerland) for small RNA library construction and subsequent sequencing by Illumina technology. Quality of the sequences was evaluated by measurement of the quality of the reads according to the percentage of bases having a base quality greater than or equal to 30 (Q30). On average, 80\% of each channel had Q30 quality. Next, 3' Illumina adapters (CTGTAGGCACCATCAAT) and " $\mathrm{N}$ " bases trimmed of the reads and sequences within the 18-28-nt range were separated for further analysis.

\section{Bioinformatics analysis}

After trimming and filtering, the remained reads were subjected to the University of East Anglia (UEA) sRNA toolkit (Plant version) miRProf, which allows the selection of conserved mature miRNA and provides the miRNA expression profile. The sRNA libraries data have been submitted to NCBI - Gene Expression Omnibus (http://www.ncbi.nlm.nih.gov/geo/) under accession number GSE47886. The miRProf was run with sRNA of minimum size $18 \mathrm{nt}$, maximum size $28 \mathrm{nt}$. This tool matches sRNA libraries with known Viridiplantae mature miRNA deposited in miRBase database release 19 (http://www. mirbase.org/ftp.shtml), using a PatMaN program. The output of the miRProf showed sequences of miRNA that had at most one mismatch with the miRBase database and contained information about total and non-redundant sequence counts. To allow comparison between libraries, counts were normalized. Normalized counts are given in reads per 1 million (RPM) and the total reads after the final trimming and filtering steps were used for normalization. The fold changes were calculated by $1 \log _{2}$ (Hs/CT). The statistical analysis (Fisher exact test) was performed with a $p$-value cutoff $<0.05$ and Bonferroni correction.

Novel miRNAs were identified in the maize libraries using the UEA sRNA toolkit (Plant version) miRCat pipeline. Sequences were mapped to the maize genome (B73 RefGen_v2) to find clusters of sRNA. The most abundant sRNA read within a cluster was chosen as the likely miRNA candidate. Only new miRNA candidates with a corresponding miRNA* were further analyzed. The flanking sequences surrounding the sRNA were extracted from the genome using a 75-nt window length. Each sequence window was then folded using RNAfold. The precursors of the miRNA candidates were tested using randfold (using a cutoff of 0.1), and an additional minimal folding free energy index (MFEI) was calculated according to Zhang et al. [99]. In order to be classified as novel miRNA, candidate sequences were searched against miRBase database release 19 using standalone BLAST [100], with default parameters. The folding structures of the new miRNA precursors identified were obtained with the UEA sRNA toolkit-RNA hairpin folding and annotation tool, which uses the Vienna Package to obtain the secondary structure of a precursor sequence, highlighting the miRNA/miRNA* sequences on the hairpin structure. Next, these precursors were mapped in the maize genome using BLASTn at MaizeGDB (http://popcorn.maizegdb. org/main/index.php) and a CViT image of the B73 assembly was created using information from the Maize Genome Sequencing Consortium [101]. Additional analyses were performed on the MaizeGDB website to compare the precursor of novel miRNA against TEs from the Maize Transposable Elements Database (http://maizetedb. org/ maize/).

\section{Prediction of miRNA targets}

To identify the putative miRNA targets, we used the Plant Small RNA Target Analysis Server, psRNA Target (http://plantgrn.noble.org/psRNATarget/). In this investigation, we used the maize genome sequence - B73 RefGen_v2, and the following parameters: maximum expectation less than 3.0; $20 \mathrm{bp}$ of length for complementarity scoring; target accessibility equal to 25; flanking length around target site for target accessibility analysis was $17 \mathrm{bp}$ in upstream and $13 \mathrm{bp}$ in downstream; and 
range of central mismatch leading to translational inhibition was 9-11 nt.

In order to obtain a functional characterization of the putative targets of conserved miRNA, the maize genome locus for each target was submitted to agriGO [39]. The singular enrichment analysis (SEA) was performed to find enriched GO terms within annotated miRNA targets.

\section{Characterization of siRNA candidates}

After the identification of miRNAs (conserved and novel), the remaining sRNAs were classified as siRNA candidates. The classification of these siRNAs was performed using two approaches: the identification of siRNA related to repeats, and siRNA related to CDSs (Coding DNA Sequences). Both analyses used the program Bowtie, release 0.12 .9 [102], to align the siRNA candidates against specific databases. Only the best reads were selected and three mismatches were allowed. In the first alignment, we used sequences of maize repeats from the Repbase, v.18 [103]; and in the second, we used maize CDS dataset of the B73 RefGen_v2. From CDSs aligned, we selected two genes that had the largest numbers of matches to nonredundant siRNA. The alignment files were converted to bam using SAMtools [104] and siRNA matches in maize CDS were quantified in Artemis.

Additional analyses were performed in Cold Spring Harbor Laboratory using their maize methylation database to identify the methylation sites in two CDS regions (GRMZM2G037875_T03 and GRMZM2G487629_T02). The identification of maize transcripts was done in the maize transcriptome database available in our laboratory. The mRNAseq was performed using the same samples used for the construction of the sRNA libraries.

\section{Validation of bioinformatics analysis by qRT-PCR}

The expression profiles of four Cu-miRNAs (miR397, miR398, miR408 and miR528) were assayed by stemloop qRT-PCR $[105,106]$. Total RNA extracted from two independent experiments of plants inoculated with $A$. brasilense, $H$. seropedicae and control plants was treated with DNaseI (Promega). Total RNA was then reverse transcribed into cDNA using Super-ScriptIII reverse transcriptase (Invitrogen). In the same reaction, RT primers specific for each miRNA sequence and random primers were used to enable the amplification of constitutive genes and of the miRNA targets. With this cDNA, qRT-PCR was used with SYBR Green PCR Master Mix (Applied Biosystems). To each well, $1 \mu \mathrm{L}$ of first strand cDNA, $5 \mu \mathrm{L}$ of SYBR Green solution, $2 \mu \mathrm{L}$ of the forward primer $(10 \mu \mathrm{M})$ and $2 \mu \mathrm{L}$ of reverse primer $(10 \mu \mathrm{M})$, designed as described in the protocol [106], were added. Two housekeeping genes were used as internal controls: Ubiquitin (F/5' AGACCCTGACTGGAAAAACC 3'; R/5' CGACC CATGACTTACTGACC $3^{\prime}$ ) and Actin (F/5' CAATGGC
ACTGGAATGGT 3'; R/5' ATCTTCAGGCGAAACACG 3'). qRT-PCR was performed using Applied Biosystems 7500 Real-Time PCR Systems. In the expression analysis of miRNA targets, the following primers were used: miR397 target (F/5' GTTCGATGTGCAAATGACCAA 3'; R/5' CCGTCACGATGCTCTTGCT 3'), miR398 target (F/5' TCTCATTATTCTCATGTGTTCTCAGTTC 3'; R/5' CGGCGACGGCAACAAG 3'), miR408 target (F/5' CCAAGAGACGCCAGTGAAGAG 3'; R/5' TACTGCC CGTTCACCGTGAT 3') and miR528 target (F/5' CCC AGCACTCATTCCATAGCA $3^{\prime}$; R/5' CCCAGCACTC ATTCCATAGCA 3').

\section{Availability of supporting data}

The data set supporting the results of this article is available in the NCBI - Gene Expression Omnibus repository, (http://www.ncbi.nlm.nih.gov/geo/) under accession number GSE47886.

\section{Additional files}

\begin{abstract}
Additional file 1: Table S1. Differential expression of conserved miRNAs in replicates of libraries. The number of reads found in each library was normalized per million, and the $\log _{2}(\mathrm{Hsb} / \mathrm{CTb})$ was calculated. CTb: control library of experiment B, Hsb: Inoculated library of experiment B. The Fisher exact test was performed with Bonferroni correction.

Additional file 2: Table S2. Predicted targets of novel miRNAs using psRNA Target. All novel miRNA sequences were denominated Zma_miR_Seq following the number, varying from 01 to 15 .

Additional file 3: Figure S3. Predicted precursor structure of novel miRNAs class I identified. The maize mature miRNA (green), miRNA* (pink) were illustrated in pre-miRNA with chromosome and locus information based in the maize genome v.2. All novel miRNA sequences were denominated Zma_miR_Seq following the number, varying from 01 to 15.

Additional file 4: Figure S4. CViT image of the B73 assembly aligned with precursor of novel miRNAs. The POPcorn website (http://popcorn. maizegdb.org/main/index.php) was used. All novel miRNA sequences were denominated Zma_miR_Seq following the number, varying from 01 to 15 .

Additional file 5: Figure S5. Analysis of siRNA and methylation profile at the splice variant of GRMZM2G487629 gene. (A) Localization of GRMZM2G487629 in chromosome 1 and two possible splice variants from this gene (boxes represent exons, and lines are introns). (B) Position of siRNA aligned in GRMZM2G487629_T02. The two peaks, blue and green, are siRNA non-redundant sequences from inoculated and control libraries, respectively. (C) Four data tracks show methylation levels for B73 in different sequence contexts. Methylation levels are displayed on a scale from 0 to 1.
\end{abstract}

\section{Competing interests}

The authors declare that they have no competing interests.

\section{Authors' contributions}

FT wrote the manuscript; CAR carried out the plant experiment and RNA extraction; FT and CG carried-out bioinformatics analyses; FT, MRM and TV performed real-time quantification; MR and RAM carried out the methylation profile analysis; PCGF and ASH coordinated the study; LF participated in the sRNA libraries construction and sequencing; PCGF critically revised the article. All authors read and approved the final manuscript. 


\section{Acknowledgements}

We are grateful to Dr. Messias Gonzaga Pereira, Universidade Estadual do Norte Fluminense (UENF), for providing maize seeds, and EMBRAPA Agrobiology for providing Azospirillum brasilense (BR11005) and Herbaspirillum seropedicae (HRC54) strains. Research by our group is supported by the Conselho Nacional de Desenvolvimento Científico e Tecnológico (CNPq), Instituto Nacional de Ciência e Tecnologia em Fixação Biológica de Nitrogênio (INCT), Financiadora de Estudos e Projetos (FINEP), Fundação de Amparo à Pesquisa do Rio de Janeiro (FAPERJ) and Coordenação de Aperfeiçoamento de Pessoal de Nível Superior (CAPES). We thank Dr. Martha Sorensen and André Ferreira for language editing.

\section{Author details}

'Laboratório de Biologia Molecular de Plantas, Instituto de Bioquímica Médica Leopoldo de Meis, Universidade Federal do Rio de Janeiro, Cidade Universitária, Avenida Carlos Chagas Filho, 373, CCS, BI.L-29ss, Rio de Janeiro RJ 21941-599, Brazil. ${ }^{2}$ Universidade Federal da INTEGRAÇÃO Latino-Americana, Av. Tancredo Neves, 6731, Bl.4, Foz do Iguaçu PR 85867-970, Brazil. ${ }^{3}$ Howard Hughes Medical Institute and Gordon and Betty Moore Foundation, Cold Spring Harbor Laboratory, Cold Spring Harbor, NY 11724, USA. ${ }^{4}$ Fasteris SA, 1228-Plan-les-Ouates, Genève, Switzerland.

Received: 8 January 2014 Accepted: 22 August 2014

Published: 6 September 2014

\section{References}

1. Bartel DP, Lee R, Feinbaum R: MicroRNAs: genomics, biogenesis, mechanism, and function genomics. Cell 2004, 116:281-297.

2. Lu C, Tej SS, Luo S, Haudenschild CD, Meyers BC, Green PJ: Elucidation of the small RNA component of the transcriptome. Science 2005, 309:1567-1569.

3. Reinhart BJ, Weinstein EG, Rhoades MW, Bartel B, Bartel DP: MicroRNAs in plants. Genes Dev 2002, 16:1616-1626.

4. Llave C, Kasschau KD, Rector MA, Carrington JC: Endogenous and silencingassociated small RNAs in plants. Society 2002, 14(July):1605-1619.

5. Axtell MJ: Classification and comparison of small RNAs from plants. Annu Rev Plant Biol 2013, 64(January):137-159.

6. Kurihara Y, Takashi Y, Watanabe Y: The interaction between DCL1 and HYL1 is important for efficient and precise processing of pri-miRNA in plant microRNA biogenesis. RNA 2006, 12:206-212.

7. Vaucheret H: Plant ARGONAUTES. Trends Plant Sci 2008, 13:350-358.

8. Brodersen P, Sakvarelidze-Achard L, Bruun-Rasmussen M, Dunoyer P, Yamamoto YY, Sieburth L, Voinnet O: Widespread translational inhibition by plant miRNAs and siRNAs. Science 2008, 320:1185-1190.

9. Jia X, Yan J, Tang G: MicroRNA-mediated DNA methylation in plants. Front Biol (Beijing) 2011, 6:133-139.

10. Guo H, Xie Q, Fei J, Chua N: MicroRNA directs mRNA cleavage of the transcription factor NAC1 to downregulate auxin signals for Arabidopsis lateral root development. Development 2005, 17(May):1376-1386.

11. Jones-Rhoades MW, Bartel DP, Bartel B: MicroRNAS and their regulatory roles in plants. Annu Rev Plant Biol 2006, 57:19-53.

12. Ma Z, Coruh C, Axtell MJ: Arabidopsis lyrata small RNAs: transient MIRNA and small interfering RNA loci within the Arabidopsis genus. Plant Cell 2010, 22:1090-1103.

13. Rajeswaran R, Aregger M, Zvereva AS, Borah BK, Gubaeva EG, Pooggin MM: Sequencing of RDR6-dependent double-stranded RNAs reveals novel features of plant siRNA biogenesis. Nucleic Acids Res 2012, 40:6241-6254.

14. Lam P, Zhao L, McFarlane HE, Aiga M, Lam V, Hooker TS, Kunst L: RDR1 and SGS3, components of RNA-mediated gene silencing, are required for the regulation of cuticular wax biosynthesis in developing inflorescence stems of Arabidopsis. Plant Physiol 2012, 159:1385-1395.

15. Garcia-Ruiz H, Takeda A, Chapman EJ, Sullivan CM, Fahlgren N, Brempelis KJ, Carrington JC: Arabidopsis RNA-dependent RNA polymerases and dicer-like proteins in antiviral defense and small interfering RNA biogenesis during Turnip Mosaic Virus infection. Plant Cell 2010, 22:481-496.

16. Qi Y, He X, Wang X-J, Kohany O, Jurka J, Hannon GJ: Distinct catalytic and non-catalytic roles of ARGONAUTE4 in RNA-directed DNA methylation. Nature 2006, 443:1008-1012.
17. Kasschau KD, Fahlgren N, Chapman EJ, Sullivan CM, Cumbie JS, Givan S, Carrington JC: Genome-wide profiling and analysis of Arabidopsis siRNAs. PLOS Biol 2007, 5:e57.

18. Daxinger L, Kanno T, Bucher E, van der Winden J, Naumann U, Matzke AJM, Matzke M: A stepwise pathway for biogenesis of 24-nt secondary siRNAs and spreading of DNA methylation. EMBO J 2009, 28:48-57.

19. Zilberman D, Cao X, Johansen LK, Xie Z, Carrington JC, Jacobsen SE: Role of Arabidopsis ARGONAUTE4 in RNA-directed DNA methylation triggered by inverted repeats. Curr Biol 2004, 14:1214-1220.

20. Simon SA, Meyers BC: Small RNA-mediated epigenetic modifications in plants. Curr Opin Plant Biol 2011, 14:148-155.

21. De Luis A, Markmann K, Cognat V, Holt DB, Charpentier M, Parniske M, Stougaard J, Voinnet O: Two microRNAs linked to nodule infection and nitrogen-fixing ability in the legume Lotus japonicus. Plant Physiol 2012, 160:2137-2154.

22. Subramanian S, Fu Y, Sunkar R, Barbazuk WB, Zhu J-K, Yu O: Novel and nodulation-regulated microRNAs in soybean roots. BMC Genomics 2008, 9:160.

23. Baldani J, Goe SR, Döbereiner J: Recent advances in FBN with non-legume plants. Soil Biol Biochem 1997, 29:911-922.

24. James EK, Olivares FL: Infection and colonization of sugar cane and other Graminaceous plants by endophytic diazotrophs. Crit Rev Plant Sci 1997, 17:77-119.

25. Kirchhof G, Reis V, Baldani J, Eckert B, Döbereiner J, Hartmann A: Occurrence, physiological and molecular analysis of endophytic diazotrophic bacteria in gramineous energy plants. Dev Plant Soil SCi 1997, 75:45-55.

26. Bothast RJ, Schlicher M: Biotechnological processes for conversion of corn into ethanol. Appl Microbiol Biotechnol 2005, 67:19-25.

27. Olivares FL, Baldani VLD, Reis VM: Occurrence of the endophytic diazotrophs Herbaspirillum spp. in roots, stems, and leaves, predominantly of Gramineae. Biol Fertil Soils 1996, 20:197-200.

28. Roesch LFW, Camargo F, Bento FM, Triplett EW: Biodiversity of diazotrophic bacteria within the soil, root and stem of field-grown maize. Plant Soil 2007, 302:91-104.

29. Riggs P, Chelius M, Iniguez A, Kaeppler S, Triplett E: Enhanced maize productivity by inoculation with diazotrophic bacteria. Aust J Plant Physiol 2001, 28:829-836.

30. Schnable PS, Ware D, Fulton RS, Stein JC, Wei F, Pasternak S, Liang C, Zhang J, Fulton L, Graves T, Minx P, Reily AD, Courtney L, Kruchowski SS, Tomlinson C, Strong C, Delehaunty K, Fronick C, Courtney B, Rock SM, Belter E, Du F, Kim K, Abbott RM, Cotton M, Levy A, Marchetto P, Ochoa K, Jackson SM, Gillam B, et al: The B73 maize genome: complexity, diversity, and dynamics. Science 2009, 326:1112-1115.

31. Zhang B, Pan X, Anderson TA: Identification of 188 conserved maize microRNAs and their targets. FEBS Lett 2006, 580:3753-3762.

32. Barber WT, Zhang W, Win H, Varala KK, Dorweiler JE, Hudson ME, Moose SP: Repeat associated small RNAs vary among parents and following hybridization in maize. Proc Natl Acad Sci U S A 2012, 109:10444-10449.

33. Kang M, Zhao Q, Zhu D, Yu J: Characterization of microRNAs expression during maize seed development. BMC Genomics 2012, 13:360.

34. Santi C, Bogusz $D$, Franche C: Biological nitrogen fixation in non-legume plants. Ann Bot 2013, 111:743-767.

35. Assmus B, Hutzler P, Kirchhof G, Amann R, Lawrence JR, Hartmann A: In situ localization of Azospirillum in the rhizosphere of wheat with fluorescently labeled, rRNA-targeted oligonucleotide probes and scanning confocal laser microscopy. Appl Environ Microbiol 1995, 61:1013-1019.

36. Oliveira ALM, Urquiaga S, Döbereiner J, Baldani Jl: The effect of inoculating endophytic $\mathrm{N} 2$-fixing bacteria on micropropagated sugarcane plants. Plant Soil 2002, 242:205-215.

37. James EK, Olivares FL, de Oliveira AL, dos Reis FB, da Silva LG, Reis VM: Further observations on the interaction between sugar cane and Gluconacetobacter diazotrophicus under laboratory and greenhouse conditions. J Exp Bot 2001, 52:747-760.

38. Dai X, Zhao PX: psRNATarget: a plant small RNA target analysis server. Nucleic Acids Res 2011, 39(May):155-159.

39. Du Z, Zhou X, Ling Y, Zhang Z, Su Z: agriGO: a GO analysis toolkit for the agricultural community. Nucleic Acids Res 2010, 38:W64-W70.

40. Mayer AM, Staples RC: Laccase: new functions for an old enzyme. Phytochemistry 2002, 60:551-565. 
41. Burkhead JL, Reynolds KAG, Abdel-Ghany SE, Cohu CM, Pilon M: Copper homeostasis. New Phytol 2009, 182:799-816.

42. Meyers BC, Axtell MJ, Bartel B, Bartel DP, Baulcombe D, Bowman JL, Cao X, Carrington JC, Chen X, Green PJ, Griffiths-Jones S, Jacobsen SE, Mallory AC, Martienssen RA, Poethig RS, Qi Y, Vaucheret $H$, Voinnet O, Watanabe $Y$, Weigel D, Zhu J-K: Criteria for annotation of plant MicroRNAs. Plant Cell 2008, 20:3186-3190.

43. Lelandais-Brière C, Naya L, Sallet E, Calenge F, Frugier F, Hartmann C, Gouzy J, Crespi M: Genome-wide Medicago truncatula small RNA analysis revealed novel microRNAs and isoforms differentially regulated in roots and nodules. Plant Cell 2009, 21:2780-2796.

44. Regulski M, Lu Z, Kendall J, Donoghue MT A, Reinders J, Llaca V, Deschamps S, Smith A, Levy D, McCombie WR, Tingey S, Rafalski A, Hicks J, Ware D, Martienssen RA: The maize methylome influences mRNA splice sites and reveals widespread paramutation-like switches guided by small RNA. Genome Res 2013, 23:1651-1662.

45. Rubio-Somoza I, Cuperus JT, Weigel D, Carrington JC: Regulation and functional specialization of small RNA-target nodes during plant development. Curr Opin Plant Biol 2009, 12:622-627.

46. Sunkar R, Chinnusamy V, Zhu J, Zhu J-K: Small RNAs as big players in plant abiotic stress responses and nutrient deprivation. Trends Plant Sci 2007. 12:301-309.

47. Khraiwesh B, Zhu JJ-KJJ-K: Role of miRNAs and siRNAs in biotic and abiotic stress responses of plants. Biochim Biophys Acta 1819, 2012:137-148.

48. Simon S, Meyers BC, Sherrier DJ: MicroRNAs in the rhizobia legume symbiosis. Plant Physiol 2009, 151:1002-1008.

49. Reinhold-Hurek B, Hurek T: Life in grasses: diazotrophic endophytes. Trends Microbiol 1998, 6:139-144.

50. Cavalcante JJV, Vargas C, Nogueira EM, Vinagre F, Schwarcz K, Baldani Jl: Members of the ethylene signalling pathway are regulated in sugarcane during the association with nitrogen-fixing endophytic bacteria. J Exp Bot 2007, 58:673-686

51. Vinagre F, Vargas C, Schwarcz K, Cavalcante J, Nogueira EM, Baldani Jl, Ferreira PCG, Hemerly AS: SHR5: a novel plant receptor kinase involved in plant-N2-fixing endophytic bacteria association. J Exp Bot 2006, 57:559-569.

52. Sevilla M, Burris R, Gunapala N, Kennedy C: Comparison of benefit to sugar cane plant growth of an $15 \mathrm{~N} 2$ incorporation following inoculation of sterile plants with Acetobacter diazotrophicus wild-type and Nif- mutant strains. Mol Plant-Microbe Interact 2001, 14:358-366.

53. Baldotto A, Baldotto B, Estrela L, Santana B, Roberto C: Initial performance of maize in response to NPK fertilization combined. Rev Ceres 2012, 59:841-849.

54. Ding D, Zhang L, Wang H, Liu Z, Zhang Z, Zheng Y: Differential expression of miRNAs in response to salt stress in maize roots. Ann Bot 2009, 103:29-38.

55. Jiao $Y$, Song $W$, Zhang M, Lai J: Identification of novel maize miRNAs by measuring the precision of precursor processing. BMC Plant Biol 2011, 11:141.

56. Ding D, Li W, Han M, Wang Y, Fu Z, Wang B, Tang J: Identification and characterisation of maize microRNAs involved in developing ears. Plant Biol 2014, 16:9-15.

57. Fahlgren N, Howell MD, Kasschau KD, Chapman EJ, Sullivan CM, Cumbie JS, Givan SA, Law TF, Grant SR, Dangl JL, Carrington JC: High-throughput sequencing of Arabidopsis microRNAs: evidence for frequent birth and death of MIRNA genes. PLoS One 2007, 2:e219.

58. Staiger D, Korneli C, Lummer M, Navarro L: Emerging role for RNA-based regulation in plant immunity. New Phytol 2013, 197:394-404.

59. Navarro L, Dunoyer P, Jay F, Arnold B, Dharmasiri N, Estelle M, Voinnet O, Jones JDG: A plant miRNA contributes to antibacterial resistance by repressing auxin signaling. Science 2006, 312:436-439.

60. Sunkar R, Girke T, Jain PK, Zhu J: Cloning and characterization of microRNAs from rice. Plant Cell 2005, 17(5):1397-1411.

61. Jones-Rhoades MW, Bartel DP: Computational identification of plant microRNAs and their targets, including a stress-induced miRNA. Mol Cell 2004, 14:787-799.

62. Zanca AS, Vicentini R, Ortiz-Morea FA, Del Bem LE V, da Silva MJ, Vincentz $M$, Nogueira FTS: Identification and expression analysis of microRNAs and targets in the biofuel crop sugarcane. BMC Plant Biol 2010, 10:260.

63. Pilon M, Abdel-Ghany SE, Cohu CM, Gogolin KA, Ye H: Copper cofactor delivery in plant cells. Curr Opin Plant Biol 2006, 9:256-263.
64. Zhang L, Chia J-M, Kumari S, Stein JC, Liu Z, Narechania A, Maher CA, Guil $\mathrm{K}$, McMullen MD, Ware D: A genome-wide characterization of microRNA genes in maize. PLoS Genet 2009, 5:e1000716.

65. Adman E: Copper protein structures. Adv Protein Chem 1991, 42:145-197.

66. Kroneck P: Redox properties of blue multi-copper oxidases. In MultiCopper Oxidases. ; 1997:391-407.

67. Liu Z, Kumari S, Zhang L, Zheng Y, Ware D: Characterization of miRNAs in response to short-term waterlogging in three inbred lines of Zea mays. PLoS One 2012, 7:e39786.

68. Lamb C, Dixon R: The oxidative burst in plant disease resistance. Annu Rev Plant Physiol Plant Mol Biol 1997, 48:251-275.

69. Bowell G, Daudi A: Reactive oxygen species in plant-pathogen interactions. In React Oxyg Species Plant Signal. ; 2009:113-133.

70. Zhang W, Gao S, Zhou X, Chellappan P, Chen Z, Zhou X, Zhang X, Fromuth $\mathrm{N}$, Coutino G, Coffey M, Jin H: Bacteria-responsive microRNAs regulate plant innate immunity by modulating plant hormone networks. Plant Mol Biol 2011, 75:93-105.

71. O'Malley DM, Whetten R, Bao W, Chen C-L, Sederoff RR: The role of of laccase in lignification. Plant J 1993, 4:751-757.

72. Jagadeeswaran G, Saini A, Sunkar R: Biotic and abiotic stress downregulate miR398 expression in Arabidopsis. Planta 2009, 229:1009-1014.

73. Fridovich I: Superoxide radical and Superoxide dismutases. Annu Rev Biochem 1995, 64:97-112.

74. Sunkar R, Kapoor A, Zhu J-K: Posttranscriptional induction of two $\mathrm{Cu} / \mathrm{Zn}$ superoxide dismutase genes in Arabidopsis is mediated by downregulation of miR398 and important for oxidative stress tolerance. Plant Cell 2006, 18:2051-2065.

75. Breakfield NW, Corcoran DL, Petricka JJ, Shen J, Sae-Seaw J, Rubio-Somoza I, Weigel D, Ohler U, Benfey PN: High-resolution experimental and computational profiling of tissue-specific known and novel miRNAs in Arabidopsis. Genome Res 2011, 22:163-176.

76. Fahlgren N, Jogdeo S, Kasschau KD, Sullivan CM, Chapman EJ, Laubinger S, Smith LM, Dasenko M, Givan SA, Weigel D, Carrington JC: MicroRNA gene evolution in Arabidopsis lyrata and Arabidopsis thaliana. Plant Cell 2010, 22:1074-1089.

77. Cuperus JT, Fahlgren N, Carrington JC: Evolution and functional diversification of MIRNA genes. Plant Cell Online 2011, 23:431-442.

78. Voinnet O: Origin, biogenesis, and activity of plant microRNAs. Cell 2009, 136:669-687.

79. Dong Z, Han M-H, Fedoroff N: The RNA-binding proteins HYL1 and SE promote accurate in vitro processing of pri-miRNA by DCL1. Proc Natl Acad Sci U S A 2008, 105:9970-9975.

80. Wu L, Zhou H, Zhang Q, Zhang J, Ni F, Liu C, Qi Y: DNA methylation mediated by a microRNA pathway. Mol Cell 2010, 38:465-475.

81. Vazquez F, Blevins T, Ailhas J, Boller T, Meins F: Evolution of Arabidopsis MIR genes generates novel microRNA classes. Nucleic Acids Res 2008, 36:6429-6438

82. Allen E, Xie Z, Gustafson AM, Sung G-H, Spatafora JW, Carrington JC Evolution of microRNA genes by inverted duplication of target gene sequences in Arabidopsis thaliana. Nat Genet 2004, 36:1282-1290.

83. Sun J, Zhou M, Mao Z, Li C: Characterization and evolution of microRNA genes derived from repetitive elements and duplication events in plants. PLoS One 2012, 7:e34092.

84. Li Y, Li C, Xia J, Jin Y: Domestication of transposable elements into MicroRNA genes in plants. PLoS One 2011, 6:e19212.

85. Nozawa M, Miura S, Nei M: Origins and evolution of microRNA genes in plant species. Genome Biol Evol 2012, 81:1-35.

86. Vicient CM: Transcriptional activity of transposable elements in maize. BMC Genomics 2010, 11:601.

87. Nobuta K, Lu C, Shrivastava R, Pillay M, De Paoli E, Accerbi M, Arteagavazquez $M$, Sidorenko $L$, Jeong $D$, Yen $Y$, Green PJ, Chandler VL, Meyers BC: Distinct size distribution of endogenous siRNAs in maize: Evidence from deep sequencing in the mop1-1 mutant. Proc Natl Acad Sci U S A 2008, 105:14958-14963.

88. Slotkin RK, Martienssen R: Transposable elements and the epigenetic regulation of the genome. Nat Rev Genet 2007, 8:272-285.

89. Grandbastien MA, Lucas H, Morel JB, Mhiri C, Vernhettes S, Casacuberta JM: The expression of the tobacco Tnt1 retrotransposon is linked to plant defense responses. Genetica 1997, 100:241-252. 
90. Takeda S, Sugimoto K, Otsuki H, Hirochika H: Transcriptional activation of the tobacco retrotransposon Tto1 by wounding and methyl jasmonate. Plant Mol Biol 1998, 36:365-376.

91. Yu A, Lepère $G$, Jay F, Wang J, Bapaume L, Wang Y, Abraham A-L, Penterman J, Fischer RL, Voinnet O, Navarro L: Dynamics and biological relevance of DNA demethylation in Arabidopsis antibacterial defense. Proc Natl Acad Sci U S A 2013, 110:2389-2394.

92. Zhang X: The epigenetic landscape of plants. Science 2008, 320:489-492.

93. Law JA, Jacobsen SE: Establishing, maintaining and modifying DNA methylation patterns in plants and animals. Nat Rev Genet 2010, 11:204-220.

94. Zemach A, McDaniel IE, Silva P, Zilberman D: Genome-wide evolutionary analysis of eukaryotic DNA methylation. Science 2010, 328:916-919.

95. Zilberman D, Gehring M, Tran RK, Ballinger T, Henikoff S: Genome-wide analysis of Arabidopsis thaliana DNA methylation uncovers an interdependence between methylation and transcription. Nat Genet 2007, 39:61-69.

96. Hoagland D, Arnon D: The water-culture method for growing plants without soil. California Agricultural Experiment Station 1950, 347:1-32.

97. James E, Reis V, Olivares F, Baldani J, Döbereiner J, Dobereiner J: Infection of sugarcane by the nitrogen-fixing bacterium Acetobacter diazotrophicus. J Exp Bot 1994, 45:757-766

98. Reis V, Olivares F, Döbereiner J: Improved methodology for isolation of Acetobacter diazotrophicus and confirmation of its endophytic habitat. World J Microbiol Biotechnol 1994, 10:401-405.

99. Zhang BH, Pan XP, Cox SB, Cobb GP, Anderson T: Evidence that miRNAs are different from other RNAs. Cell Mol Life Sci 2006, 63:246-254.

100. Altschul SF, Gish W, Miller W, Myers EW, Lipman DJ: Basic local alignment search tool. J Mol Biol 1990, 215:403-410.

101. Lawrence CJ, Harper LC, Schaeffer ML, Sen TZ, Seigfried TE, Campbell DA: MaizeGDB: The maize model organism database for basic, translational, and applied research. Int J Plant Genomics 2008, 2008:496957.

102. Langmead B, Trapnell C, Pop M, Salzberg SL: Ultrafast and memoryefficient alignment of short DNA sequences to the human genome. Genome Biol 2009, 10:R25.

103. Jurka J, Kapitonov W, Pavlicek A, Klonowski P, Kohany O, Walichiewicz J: Repbase Update, a database of eukaryotic repetitive elements. Cytogenet Genome Res 2005, 110:462-467.

104. Li H, Handsaker B, Wysoker A, Fennell T, Ruan J, Homer N, Marth G, Abecasis G, Durbin R: The Sequence Alignment/Map format and SAMtools. Bioinformatics 2009, 25:2078-2079.

105. Chen C, Ridzon DA, Broomer AJ, Zhou Z, Lee DH, Nguyen JT, Barbisin M, Xu NL, Mahuvakar VR, Andersen MR, Lao KQ, Livak KJ, Guegler KJ: Real-time quantification of microRNAs by stem-loop RT-PCR. Nucleic Acids Res 2005, 33:e179.

106. Varkonyi-Gasic E, Wu R, Wood M, Walton EF, Hellens RP: Protocol: a highly sensitive RT-PCR method for detection and quantification of microRNAs. Plant Methods 2007, 3:12

doi:10.1186/1471-2164-15-766

Cite this article as: Thiebaut et al:: Genome-wide identification of microRNA and siRNA responsive to endophytic beneficial diazotrophic bacteria in maize. BMC Genomics 2014 15:766.

\section{Submit your next manuscript to BioMed Central and take full advantage of:}

- Convenient online submission

- Thorough peer review

- No space constraints or color figure charges

- Immediate publication on acceptance

- Inclusion in PubMed, CAS, Scopus and Google Scholar

- Research which is freely available for redistribution

Submit your manuscript at www.biomedcentral.com/submit
Ciomed Central 